Supplement of Atmos. Chem. Phys. Discuss., 15, 157-198, 2015

http://www.atmos-chem-phys-discuss.net/15/157/2015/

doi:10.5194/acpd-15-157-2015-supplement

(C) Author(s) 2015. CC Attribution 3.0 License.

(c) (i)

Gas and aerosol carbon in California: comparison of measurements and model predictions in Pasadena and Bakersfield

K. R. Baker et al.

Correspondence to: K. R. Baker (baker.kirk@epa.gov) 


\section{Emission Inventory}

Table S1a. Episode total emissions (tons) of primarily emitted PM2.5 organic carbon by area delineated by source classification code (SCC). The Los Angeles (LA) total includes Los Angeles and Orange counties. The southern San Joaquin Valley (SSJV) total includes Kern, Fresno, Kings, and Tulare counties. Only categories above $1 \%$ contribution shown.

\begin{tabular}{|c|c|c|c|c|}
\hline Area & Tons & Percent & SCC7 & SCC7 Description \\
\hline SSJV & 72.0 & 17.4 & 2302002 & Industrial Processes;Food and Kindred Products: SIC 20;Commercial Cooking - Charbroiling \\
\hline SSJV & 54.1 & 13.1 & 2104008 & Stationary Source Fuel Combustion;Residential;Wood \\
\hline SSJV & 49.3 & 11.9 & 2801500 & Miscellaneous Area Sources;Agriculture Production - Crops;Agricultural Field Burning - whole field set on fire \\
\hline SSJV & 28.4 & 6.9 & 310004 & Industrial Processes;Oil and Gas Production;Process Heaters \\
\hline SSJV & 25.4 & 6.1 & 2230074 & Mobile Sources;Highway Vehicles - Diesel;Heavy Duty Diesel Vehicles (HDDV) Class 8A \& 8B \\
\hline SSJV & 14.7 & 3.5 & 2201001 & Mobile Sources; Highway Vehicles - Gasoline;Light Duty Gasoline Vehicles (LDGV) \\
\hline SSJV & 13.5 & 3.3 & 2294000 & Mobile Sources;Paved Roads;All Paved Roads \\
\hline SSJV & 12.9 & 3.1 & 2282005 & Mobile Sources;Pleasure Craft;Gasoline 2-Stroke \\
\hline SSJV & 12.9 & 3.1 & 101009 & External Combustion Boilers;Electric Generation;Wood/Bark Waste \\
\hline SSJV & 11.3 & 2.7 & 202002 & Internal Combustion Engines; Industrial;Natural Gas \\
\hline SSJV & 10.5 & 2.5 & 2201020 & Mobile Sources; Highway Vehicles - Gasoline;Light Duty Gasoline Trucks 1 \& 2 (M6) = LDGT1 (M5) \\
\hline SSJV & 8.9 & 2.1 & 305006 & Industrial Processes;Mineral Products;Cement Manufacturing (Dry Process) \\
\hline SSJV & 8.8 & 2.1 & 2230073 & Mobile Sources; Highway Vehicles - Diesel;Heavy Duty Diesel Vehicles (HDDV) Class 6 \& 7 \\
\hline SSJV & 6.2 & 1.5 & 2265003 & Mobile Sources;Off-highway Vehicle Gasoline, 4-Stroke;Industrial Equipment \\
\hline SSJV & 6.0 & 1.4 & 2610000 & Waste Disposal, Treatment, and Recovery;Open Burning;All Categories \\
\hline SSJV & 5.4 & 1.3 & 2296000 & Mobile Sources; Unpaved Roads;All Unpaved Roads \\
\hline SSJV & 5.4 & 1.3 & 2201040 & Mobile Sources; Highway Vehicles - Gasoline;Light Duty Gasoline Trucks 3 \& 4 (M6) = LDGT2 (M5) \\
\hline LA & 269.4 & 26.8 & 2302002 & Industrial Processes;Food and Kindred Products: SIC 20;Commercial Cooking - Charbroiling \\
\hline LA & 95.9 & 9.5 & 2282005 & Mobile Sources;Pleasure Craft;Gasoline 2-Stroke \\
\hline LA & 94.0 & 9.4 & 2201001 & Mobile Sources; Highway Vehicles - Gasoline;Light Duty Gasoline Vehicles (LDGV) \\
\hline LA & 82.7 & 8.2 & 2104008 & Stationary Source Fuel Combustion;Residential;Wood \\
\hline LA & 66.6 & 6.6 & 2307000 & Industrial Processes; Wood Products: SIC 24;All Processes \\
\hline LA & 58.0 & 5.8 & 2201020 & Mobile Sources; Highway Vehicles - Gasoline;Light Duty Gasoline Trucks 1 \& 2 (M6) = LDGT1 (M5) \\
\hline LA & 38.4 & 3.8 & 2230074 & Mobile Sources;Highway Vehicles - Diesel;Heavy Duty Diesel Vehicles (HDDV) Class 8A \& 8B \\
\hline LA & 29.9 & 3.0 & 2201040 & Mobile Sources; Highway Vehicles - Gasoline;Light Duty Gasoline Trucks 3 \& 4 (M6) = LDGT2 (M5) \\
\hline LA & 23.8 & 2.4 & 2104006 & Stationary Source Fuel Combustion;Residential;Natural Gas \\
\hline LA & 17.5 & 1.7 & 2103008 & Stationary Source Fuel Combustion;Commercial/Institutional;Wood \\
\hline LA & 15.0 & 1.5 & 2230073 & Mobile Sources; Highway Vehicles - Diesel;Heavy Duty Diesel Vehicles (HDDV) Class 6 \& 7 \\
\hline LA & 13.6 & 1.4 & 2294000 & Mobile Sources; Paved Roads;All Paved Roads \\
\hline LA & 12.0 & 1.2 & 2302080 & Industrial Processes;Food and Kindred Products: SIC 20;Miscellaneous Food and Kindred Products \\
\hline LA & 10.8 & 1.1 & 2265004 & Mobile Sources;Off-highway Vehicle Gasoline, 4-Stroke;Lawn and Garden Equipment \\
\hline LA & 10.7 & 1.1 & 2265006 & Mobile Sources;Off-highway Vehicle Gasoline, 4-Stroke;Commercial Equipment \\
\hline
\end{tabular}


Table S1b. Episode total emissions (tons) of the sum of benzene, toluene, and xylenes by area delineated by source classification code (SCC). The Los Angeles (LA) total includes Los Angeles and Orange counties. The southern San Joaquin Valley (SSJV) total includes Kern, Fresno, Kings, and Tulare counties. Only categories above $1 \%$ contribution shown.

\begin{tabular}{|c|c|c|c|c|}
\hline Area & Tons & Percent & SCC7 & SCC7 Description \\
\hline SSJV & 112.3 & 12.8 & 2201001 & Mobile Sources;Highway Vehicles - Gasoline;Light Duty Gasoline Vehicles (LDGV) \\
\hline SSJV & 81.1 & 9.2 & 2201020 & Mobile Sources; Highway Vehicles - Gasoline;Light Duty Gasoline Trucks 1 \& 2 (M6) = LDGT1 (M5) \\
\hline SSJV & 71.3 & 8.1 & 2680001 & Waste Disposal, Treatment, and Recovery;Composting; $100 \%$ Biosolids (e.g., sewage sludge, manure, mixtures of these matls) \\
\hline SSJV & 44.2 & 5.0 & 2440000 & Solvent Utilization;Miscellaneous Industrial;All Processes \\
\hline SSJV & 41.8 & 4.8 & 2201040 & Mobile Sources; Highway Vehicles - Gasoline;Light Duty Gasoline Trucks 3 \& 4 (M6) = LDGT2 (M5) \\
\hline SSJV & 35.7 & 4.1 & 2460000 & Solvent Utilization;Miscellaneous Non-industrial: Consumer and Commercial;All Processes \\
\hline SSJV & 32.5 & 3.7 & 2282005 & Mobile Sources;Pleasure Craft;Gasoline 2-Stroke \\
\hline SSJV & 31.9 & 3.6 & 2265004 & Mobile Sources;Off-highway Vehicle Gasoline, 4-Stroke;Lawn and Garden Equipment \\
\hline SSJV & 31.5 & 3.6 & 2310010 & Industrial Processes;Oil and Gas Production: SIC 13;Crude Petroleum \\
\hline SSJV & 30.6 & 3.5 & 2620030 & Waste Disposal, Treatment, and Recovery;Landfills;Municipal \\
\hline SSJV & 27.6 & 3.1 & 2265001 & Mobile Sources;Off-highway Vehicle Gasoline, 4-Stroke;Recreational Equipment \\
\hline SSJV & 25.6 & 2.9 & 309010 & Industrial Processes;Fabricated Metal Products;Electroplating Operations \\
\hline SSJV & 20.6 & 2.4 & 2282010 & Mobile Sources;Pleasure Craft;Gasoline 4-Stroke \\
\hline SSJV & 16.5 & 1.9 & 2401002 & Solvent Utilization;Surface Coating;Architectural Coatings - Solvent-based \\
\hline SSJV & 15.1 & 1.7 & 2201070 & Mobile Sources;Highway Vehicles - Gasoline;Heavy Duty Gasoline Vehicles 2B thru 8B \& Buses (HDGV) \\
\hline SSJV & 14.8 & 1.7 & 2265005 & Mobile Sources;Off-highway Vehicle Gasoline, 4-Stroke;Agricultural Equipment \\
\hline SSJV & 14.7 & 1.7 & 2401005 & Solvent Utilization;Surface Coating;Auto Refinishing: SIC 7532 \\
\hline SSJV & 14.6 & 1.7 & 2401020 & Solvent Utilization;Surface Coating;Wood Furniture: SIC 25 \\
\hline SSJV & 12.0 & 1.4 & 2801500 & Miscellaneous Area Sources;Agriculture Production - Crops;Agricultural Field Burning - whole field set on fire \\
\hline SSJV & 11.3 & 1.3 & 2265003 & Mobile Sources;Off-highway Vehicle Gasoline, 4-Stroke;Industrial Equipment \\
\hline SSJV & 10.9 & 1.2 & 2260004 & Mobile Sources;Off-highway Vehicle Gasoline, 2-Stroke;Lawn and Garden Equipment \\
\hline SSJV & 10.6 & 1.2 & 2230074 & Mobile Sources; Highway Vehicles - Diesel; Heavy Duty Diesel Vehicles (HDDV) Class 8A \& 8B \\
\hline SSJV & 10.3 & 1.2 & 2415300 & Solvent Utilization;Degreasing;All Industries: Cold Cleaning \\
\hline SSJV & 10.1 & 1.2 & 2265006 & Mobile Sources;Off-highway Vehicle Gasoline, 4-Stroke;Commercial Equipment \\
\hline SSJV & 10.1 & 1.2 & 2460500 & Solvent Utilization;Miscellaneous Non-industrial: Consumer and Commercial;All Coatings and Related Products \\
\hline SSJV & 9.5 & 1.1 & 2501011 & Storage and Transport;Petroleum and Petroleum Product Storage;Residential Portable Gas Cans \\
\hline SSJV & 9.2 & 1.0 & 2201080 & Mobile Sources; Highway Vehicles - Gasoline;Motorcycles (MC) \\
\hline LA & 546.0 & 15.9 & 2201001 & Mobile Sources; Highway Vehicles - Gasoline;Light Duty Gasoline Vehicles (LDGV) \\
\hline LA & 345.8 & 10.1 & 2201020 & Mobile Sources; Highway Vehicles - Gasoline;Light Duty Gasoline Trucks 1 \& 2 (M6) = LDGT1 (M5) \\
\hline LA & 244.8 & 7.1 & 2265004 & Mobile Sources;Off-highway Vehicle Gasoline, 4-Stroke;Lawn and Garden Equipment \\
\hline LA & 207.7 & 6.0 & 2282005 & Mobile Sources;Pleasure Craft;Gasoline 2-Stroke \\
\hline LA & 201.2 & 5.9 & 2460000 & Solvent Utilization;Miscellaneous Non-industrial: Consumer and Commercial;All Processes \\
\hline LA & 178.1 & 5.2 & 2201040 & Mobile Sources; Highway Vehicles - Gasoline;Light Duty Gasoline Trucks 3 \& 4 (M6) = LDGT2 (M5) \\
\hline LA & 114.0 & 3.3 & 2401050 & Solvent Utilization;Surface Coating;Miscellaneous Finished Metals: SIC 34 - $(341+3498)$ \\
\hline LA & 106.8 & 3.1 & 2282010 & Mobile Sources;Pleasure Craft;Gasoline 4-Stroke \\
\hline LA & 104.9 & 3.0 & 2620030 & Waste Disposal, Treatment, and Recovery;Landfills;Municipal \\
\hline LA & 88.2 & 2.6 & 2260004 & Mobile Sources;Off-highway Vehicle Gasoline, 2-Stroke;Lawn and Garden Equipment \\
\hline LA & 84.1 & 2.4 & 2401005 & Solvent Utilization;Surface Coating;Auto Refinishing: SIC 7532 \\
\hline LA & 74.4 & 2.2 & 2265006 & Mobile Sources;Off-highway Vehicle Gasoline, 4-Stroke;Commercial Equipment \\
\hline LA & 70.6 & 2.1 & 2401090 & Solvent Utilization;Surface Coating;Miscellaneous Manufacturing \\
\hline LA & 70.1 & 2.0 & 2460500 & Solvent Utilization;Miscellaneous Non-industrial: Consumer and Commercial;All Coatings and Related Products \\
\hline LA & 69.1 & 2.0 & 2415300 & Solvent Utilization;Degreasing;All Industries: Cold Cleaning \\
\hline LA & 63.3 & 1.8 & 2201070 & Mobile Sources; Highway Vehicles - Gasoline; Heavy Duty Gasoline Vehicles 2B thru 8B \& Buses (HDGV) \\
\hline LA & 58.7 & 1.7 & 306888 & Industrial Processes;Petroleum Industry;Fugitive Emissions \\
\hline LA & 56.5 & 1.6 & 2401025 & Solvent Utilization;Surface Coating;Metal Furniture: SIC 25 \\
\hline LA & 55.9 & 1.6 & 2501011 & Storage and Transport;Petroleum and Petroleum Product Storage; Residential Portable Gas Cans \\
\hline LA & 41.8 & 1.2 & 2440000 & Solvent Utilization;Miscellaneous Industrial;All Processes \\
\hline LA & 40.4 & 1.2 & 2401040 & Solvent Utilization;Surface Coating;Metal Cans: SIC 341 \\
\hline LA & 39.8 & 1.2 & 2265003 & Mobile Sources; Off-highway Vehicle Gasoline, 4-Stroke;Industrial Equipment \\
\hline LA & 39.5 & 1.1 & 2401070 & Solvent Utilization;Surface Coating;Motor Vehicles: SIC 371 \\
\hline LA & 38.7 & 1.1 & 2201080 & Mobile Sources; Highway Vehicles - Gasoline;Motorcycles (MC) \\
\hline LA & 36.9 & 1.1 & 2265001 & Mobile Sources;Off-highway Vehicle Gasoline, 4-Stroke;Recreational Equipment \\
\hline
\end{tabular}




\section{Matching Measured and Modeled Species}

Table S2a. Matching grouped measured and modeled SOA species. Measured SOC contributions estimated by dividing the total tracer concentration by group with a photochemical reaction chamber derived SOC mass fraction for the same group.

\section{Species}

Measured Species

EC

PM2.5 Elemental Carbon

PM2.5 Organic Carbon

CMAQ Model Species

$\mathrm{AECl}+\mathrm{AECJ}$

$(A X Y L 1 J+A X Y L 2 J+A X Y L 3 J) / 2.0+($ ATOL1J + ATOL2J + ATOL3J) $/ 2.0+$

$(A B N Z 1 J+A B N Z 2 J+A B N Z 3 J) / 2.0+(A I S O 1 J+A I S O 2 J) / 1.6+$ AISO3J $/ 2.7+($ ATRP1J + ATRP2J) $/ 1.4+$ ASQTJ $/ 2.1+0.64 * A A L K J+$ AORGCJ $/ 2.0+(A O L G B J+A O L G A J) / 2.1+A P O C J+A P O C I$

PM2.5 SOA species (ugC $/ \mathrm{m}^{3}$ ) Isoprene

(2-methyl erythritol + 2-methyl trietol +2 -

$(\mathrm{AISO} 1 \mathrm{~J}+\mathrm{AISO} \mathrm{J}) / 1.6+\mathrm{AISO} 3 \mathrm{~J} / 2.7+(\mathrm{AOLGBJ} / 2.1 *$ iso_fraction $)$ methylglyceric acid $) *(1 / 0.063)$

Monoterpenes

(3-acetyl hexanedioic acid + 3-hydroxygluta ric acid + 3-methyl-1,2,3 buanetricarboxylic acid + 3-a cetyl pentanedioic acid + Pinic acid + 2-hydroxy-4,4dimethyl glutaric acid $) *(1 / 0.231)$

Sesquiterpenes

(b-caryophellinic acid) * (1/0.023)

ASQT/2.1 + (AOLGB/2.1 * (1-trp_fraction-iso_fraction) )

Toluenes + Xylenes (2-3-dihydroxy-4-oxo-pentanioc a cid) * (1/0.0079)

Benzenes $\mathrm{n} / \mathrm{a}$

Alkanes

$n / a$

Methylgloxal + glyoxal

Napthhalene

$\mathrm{n} / \mathrm{a}$

(phthlaic acid + isophthalic a cid) * (1/0.0357)

(ATOL1J + ATOL2J + ATOL3J + AXYL1J + AXYL2J + AXYL3J) $/ 2$ $($ AOLGAJ $/ 2.1 *$ (tol+xyl_fraction))

$(A B N Z 1 J+A B N Z 2 J+A B N Z 3 J) / 2+(A O L G A J / 2.1 *$ bnz_fraction $)$

AALKJ $/ 1.56+($ AOLGAJ $/ 2.1 *$ alk_fraction $)$

AORGCJ/2

iso_fraction $=($ AISO1J + AISO2J + AISO3J) $/($ AISO1J +AISO2J +AISO3J +ATRP1J ATRP2J +ASQT

trp_fraction $=(A T R P 1 \mathrm{~J}+\mathrm{A} T R P \mathrm{~J}) /(\mathrm{AISO} 1 \mathrm{~J}+\mathrm{AISO} 2 \mathrm{~J}+\mathrm{AISO} 3 \mathrm{~J}+\mathrm{ATRP} 1 \mathrm{~J}$ ATRP2 $\mathrm{J}+\mathrm{ASQT})$

bnz fraction $=(A B N Z 1+A B N Z 2 J+A B N Z 3 J) /(A T O L 1 J+A T O L 2 J+A T O L 3 J+A X Y L 1+A X Y L 2 J+A X Y L 3 J+A B N Z 1+A B N Z 2 J+A B N Z 3 J+A A L K J)$

alk fraction $=(A A L K J) /(A T O L 1 J+A T O L 2 J+A T O L 3 J+A X Y L 1 J+A X Y L 2 J+A X Y L 3 J+A B N Z 1 J+A B N Z 2 J+A B N Z 3 J+A A L K J)$

tol+Xyl_fraction $=(A T O L 1 J+A T O L 2 J+A T O L 3 J+A X Y L 1 J+A X Y L 2 J+A X Y L 3 J) /(A T O L 1 J+A T O L 2 J+A T O L 3 J+A X Y L 1 J+A X Y L 2 J+A X Y L 3 J+A B N Z 1 J+A B N Z 2 J+A B N Z 3 J+A A L K J)$ 
Table S2b. Matching grouped measured and modeled VOC species.

Species

Measured Species

CMAQ Model Species

Gas Species (ppbC)

Isoprene

Isoprene $5 *$ ISOPRENE

Benzenes

Benzene

6*BENZENE

Monoterpenes

beta-pinene + alpha-pinene +2 -carene +

$10 *$ TERP

Sesquiterpenes

limonene

Toluenes

$\mathrm{n} / \mathrm{a}$

$15 *$ SESQ

Toluene + Ethylbenzene + Is opropylbenzene $* 0.78+7 *$ TOLUENE

n-propylbenzene 0.78

Xylenes

m-p xylene +o-xylene + m-ethyltoluene*0.89+p-

$8 *(M X Y L+O X Y L+P X Y L)$

ethyl toluene*0.89+1,3,5-trimethyl benzene*0.89+

o-ethyl toluene ${ }^{*} 0.89+1,2,4$-trime thyl benzene $* 0.89$

+ p-diethylbenzene ${ }^{*} 0.80$

\begin{tabular}{|c|c|c|}
\hline Ethane & Ethane & 2*ALK1 \\
\hline Ethene & Ethene & $2 *$ ETHENE \\
\hline Formaldehyde & Formaldehyde & $\mathrm{HCHO}$ \\
\hline Methanol & Methanol & $\mathrm{MEOH}$ \\
\hline Ethanol & Ethanol & $2 * \mathrm{ETOH}$ \\
\hline Total VOC (non-methane) & Sum of all measured non-methane VOC species & 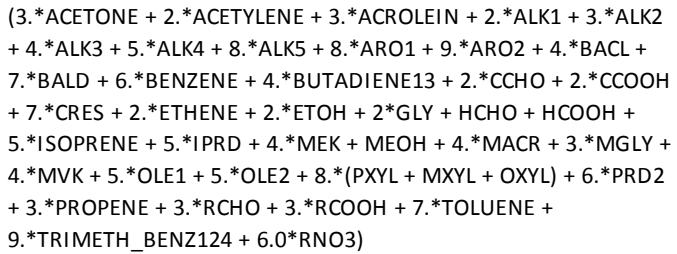 \\
\hline
\end{tabular}


Figure S1. Model domain and CALNEX monitor locations.

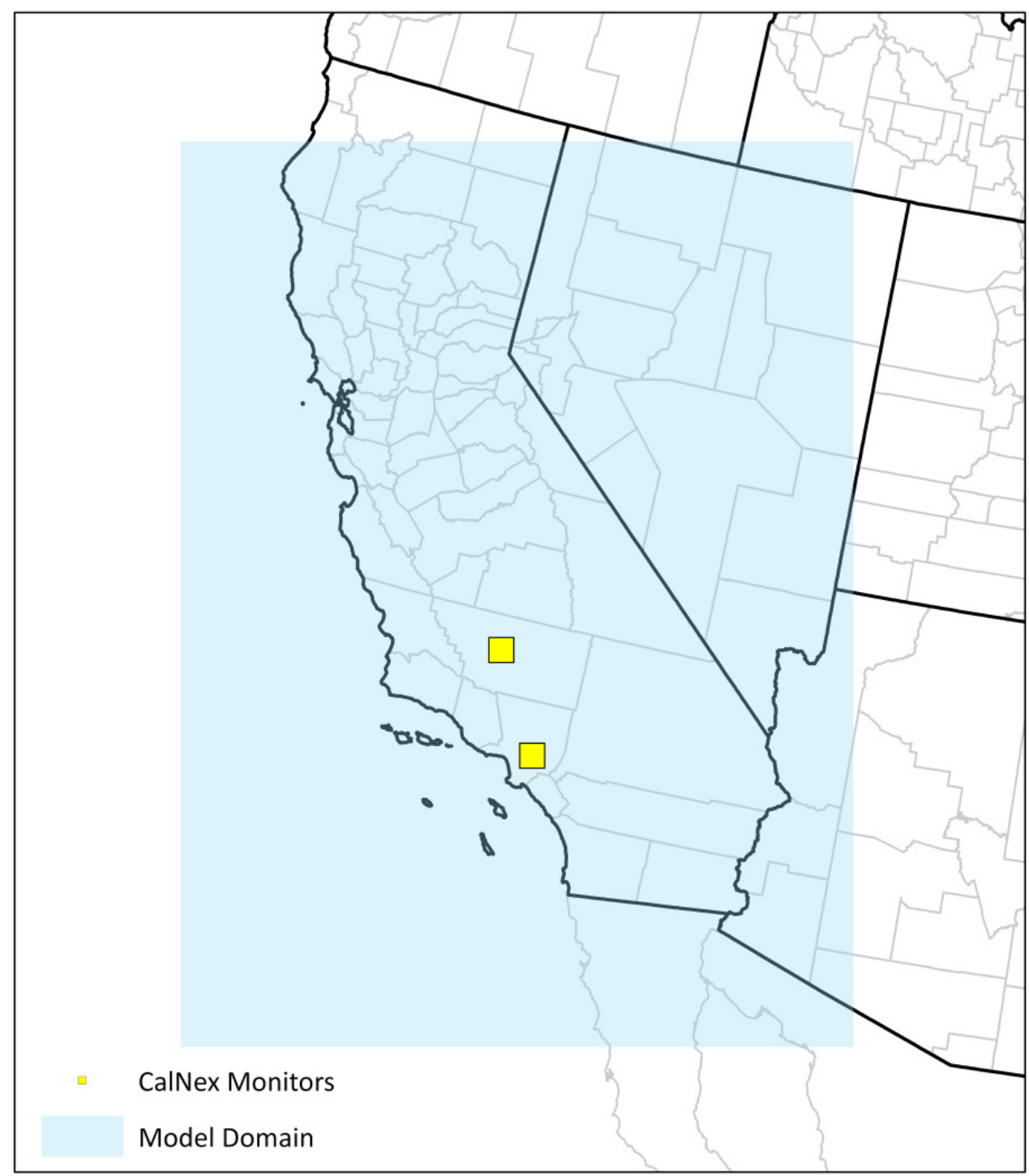


Figure S2. CMAQ SOA schematic diagram. Reproduced from Carlton et al., 2010: Carlton, A.G., Bhave, P.V., Napelenok, S.L., Edney, E.O., Sarwar, G., Pinder, R.W., Pouliot, G.A., Houyoux, M., 2010. Treatment of secondary organic aerosol in CMAQv4.7. Environmental Science and Technology 44, 8553-8560.

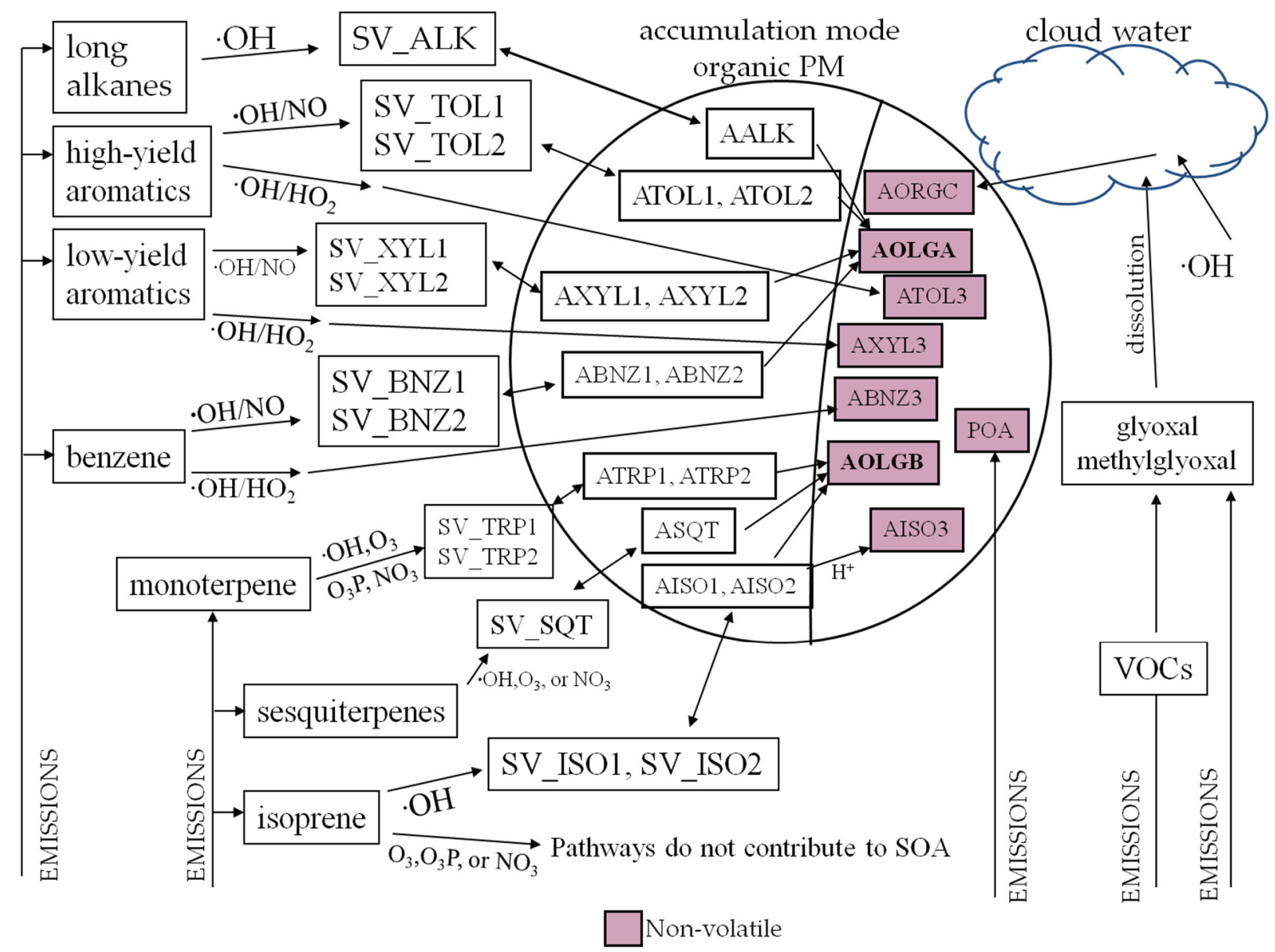


Figure S3a. Bakersfield CALNEX site and nearby CSN location.

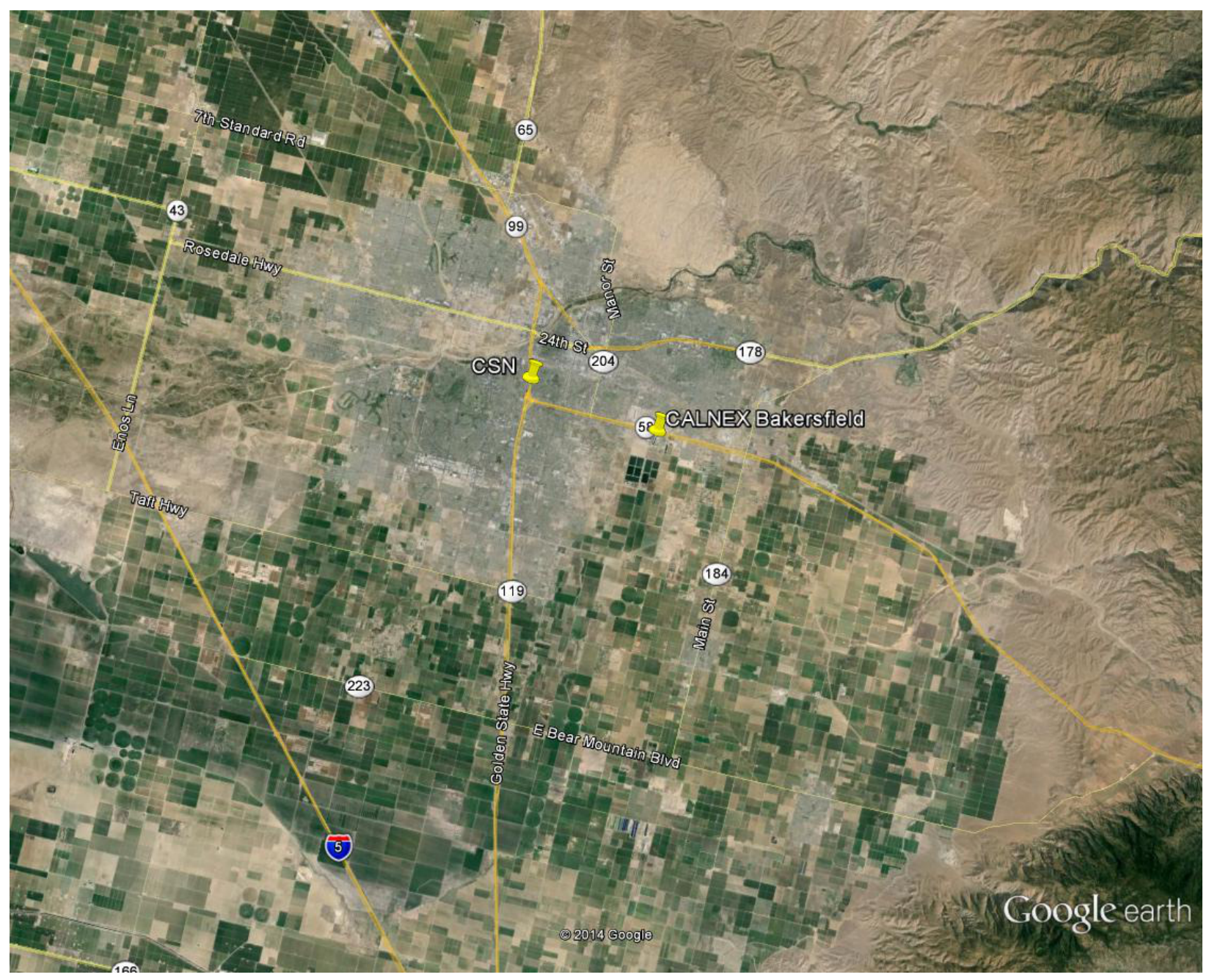


Figure S3b. Pasadena CALNEX site and nearby CSN location.

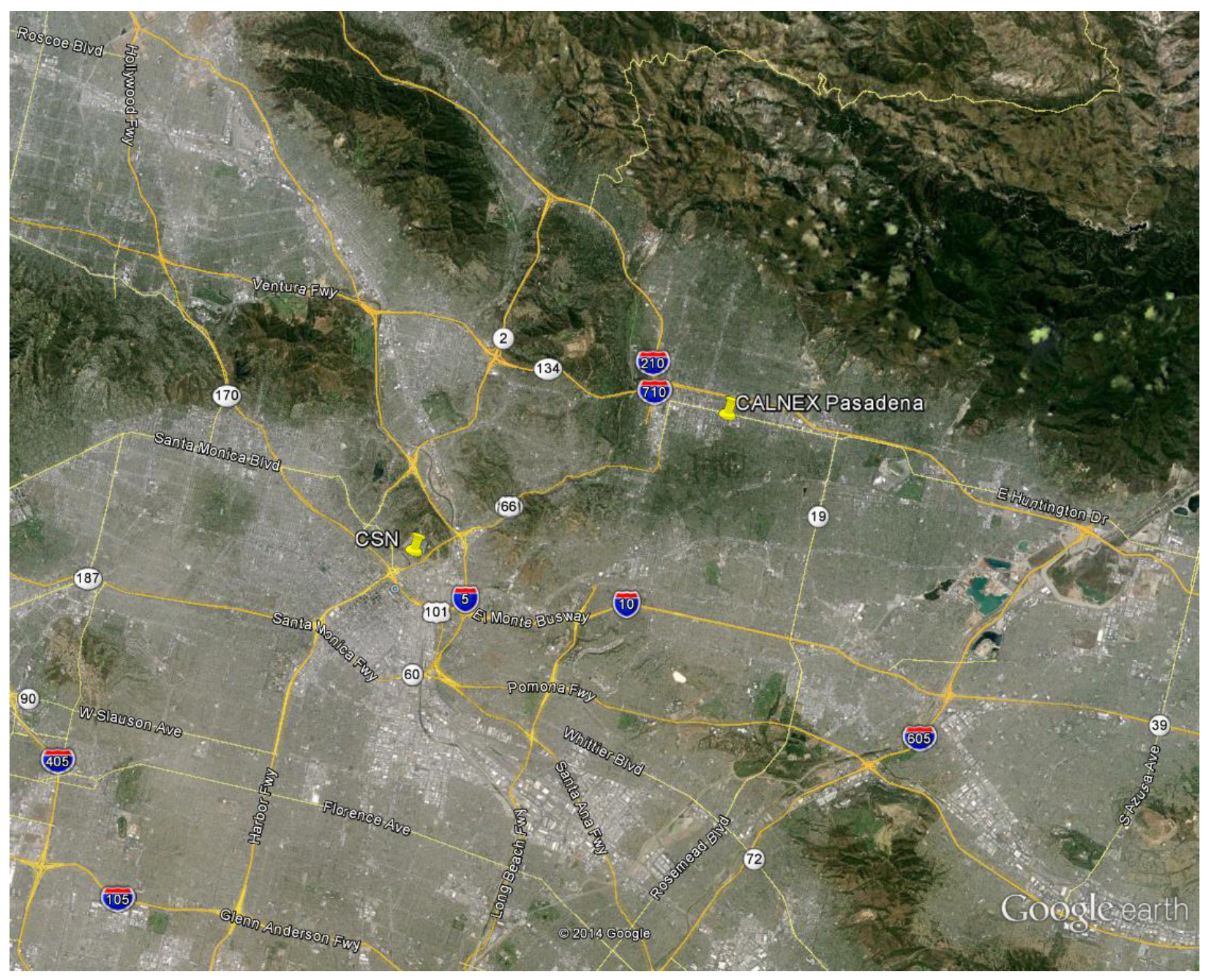


Figure S4a. Observed daily average temperature compared with daily average PM2.5 fossil carbon, PM2.5 contemporary carbon, PM2.5 organic carbon, and PM2.5 elemental carbon at Pasadena.

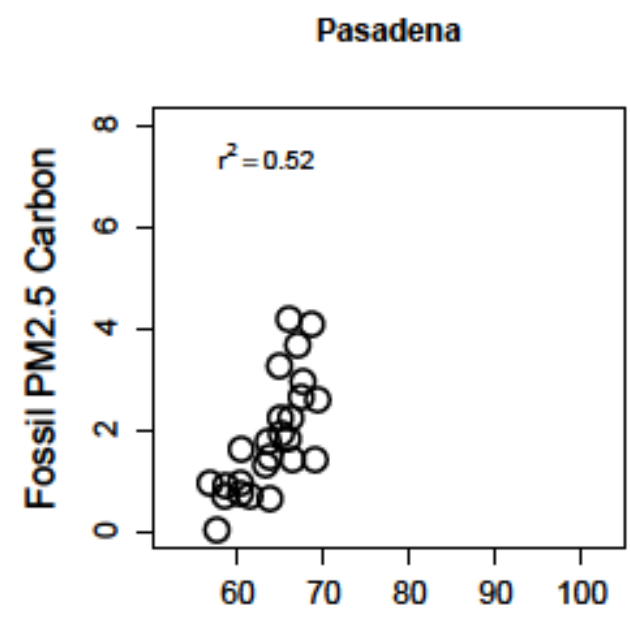

Avg Temperature (F)

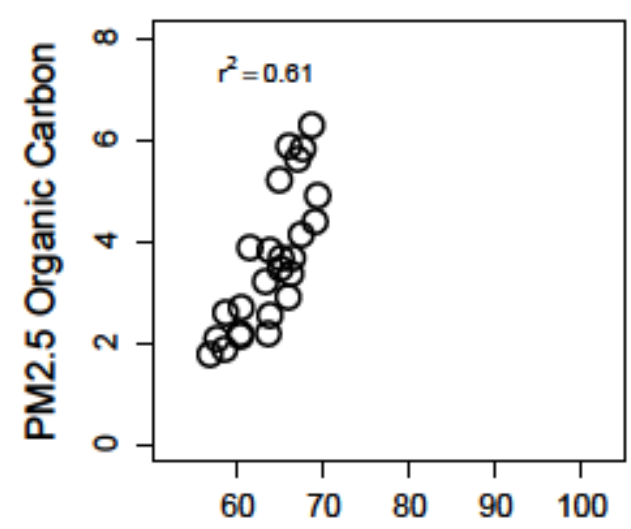

Avg Temperature (F)
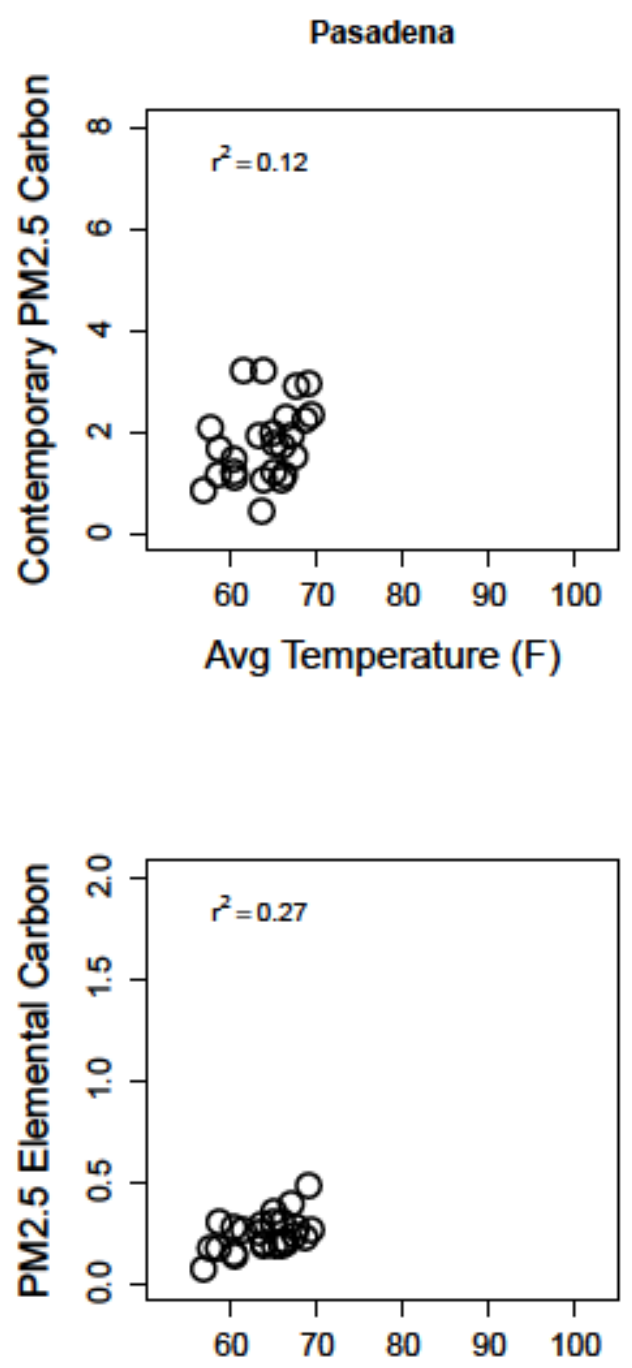

Avg Temperature (F) 
Figure S4b. Observed daily average temperature compared with daily average PM2.5 fossil carbon, PM2.5 contemporary carbon, PM2.5 organic carbon, and PM2.5 elemental carbon at Bakersfield.

Bakersfield

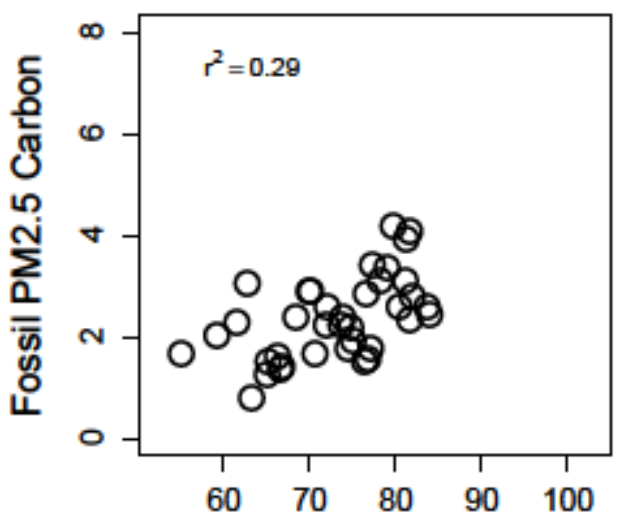

Avg Temperature (F)

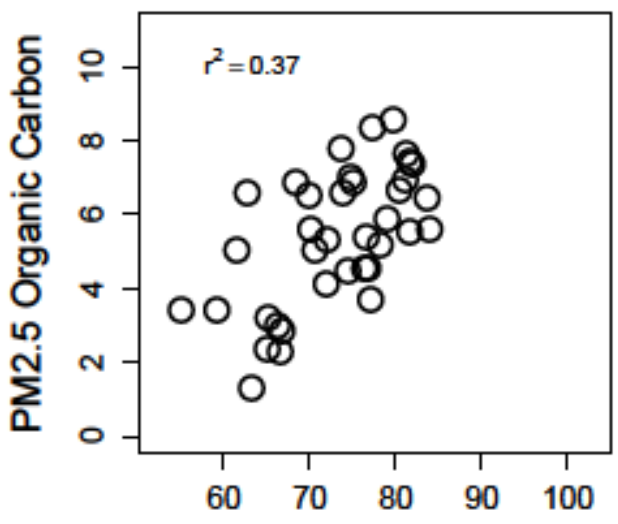

Avg Temperature (F)
Bakersfield

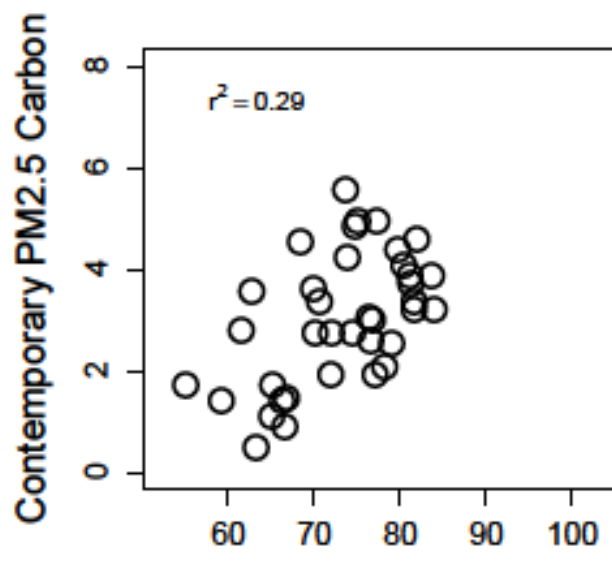

Avg Temperature (F)

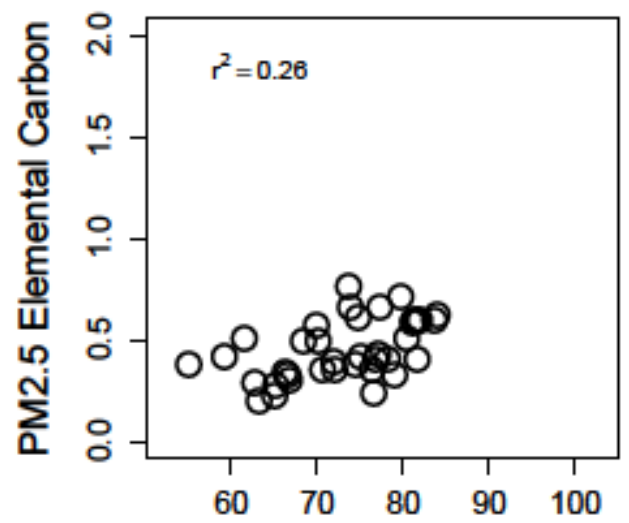

Avg Temperature (F) 
Figure S5. Observed contemporary carbon fraction, PM2.5 contemporary carbon, PM2.5 fossil carbon, and PM2.5 elemental carbon by day of the week for Pasadena and Bakersfield.

Contemporary PM2.5 OC Fraction

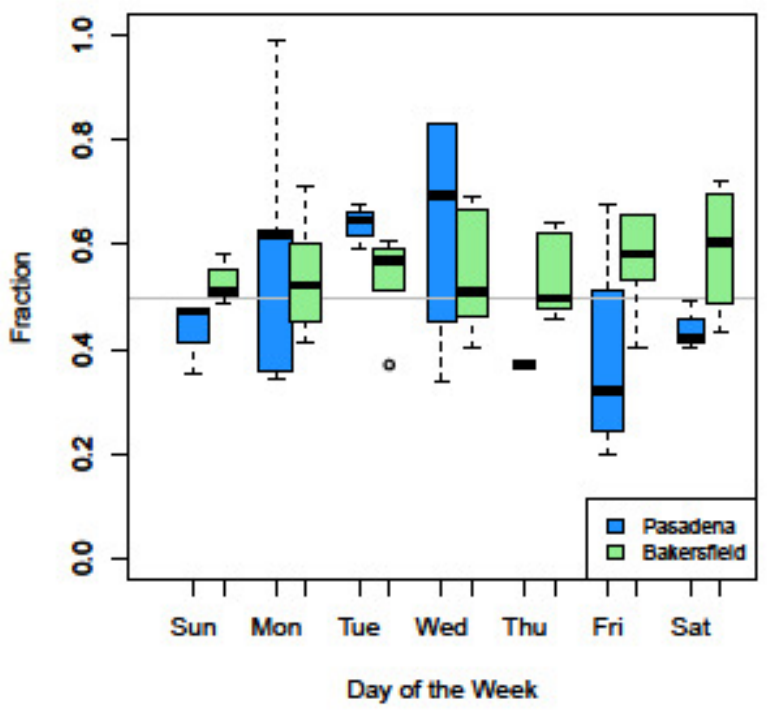

Fossil PM2.5 OC

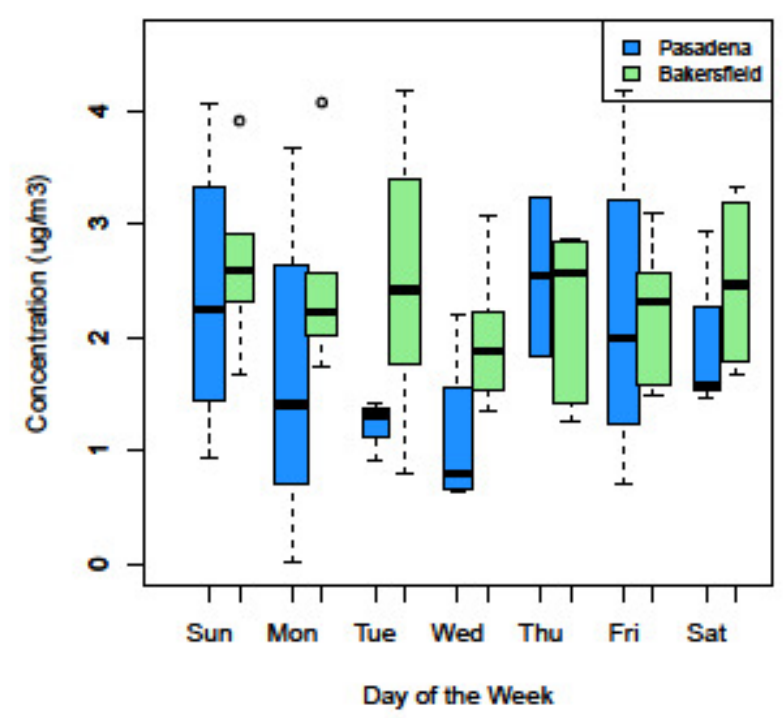

Contemporary PM2.5 OC

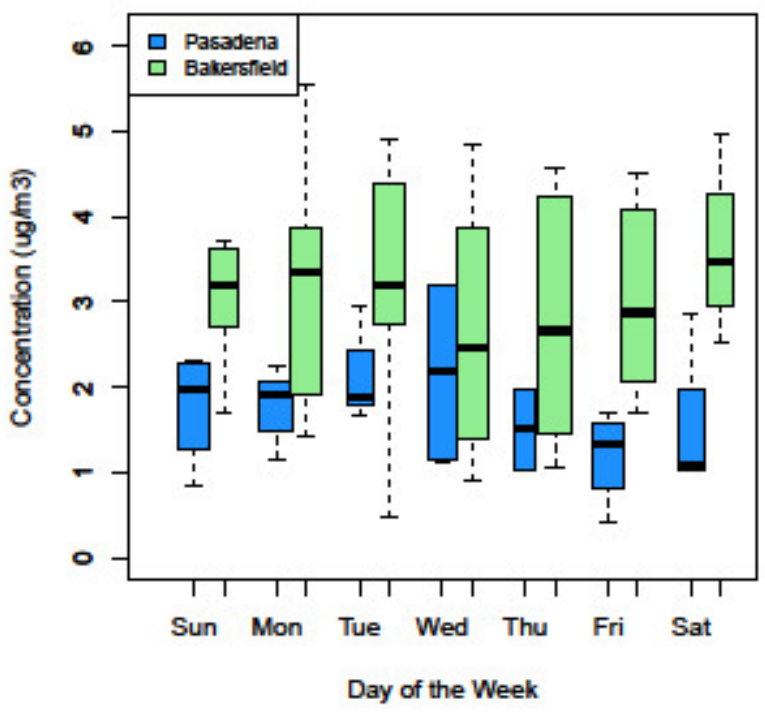

PM2.5 Elemental Carbon

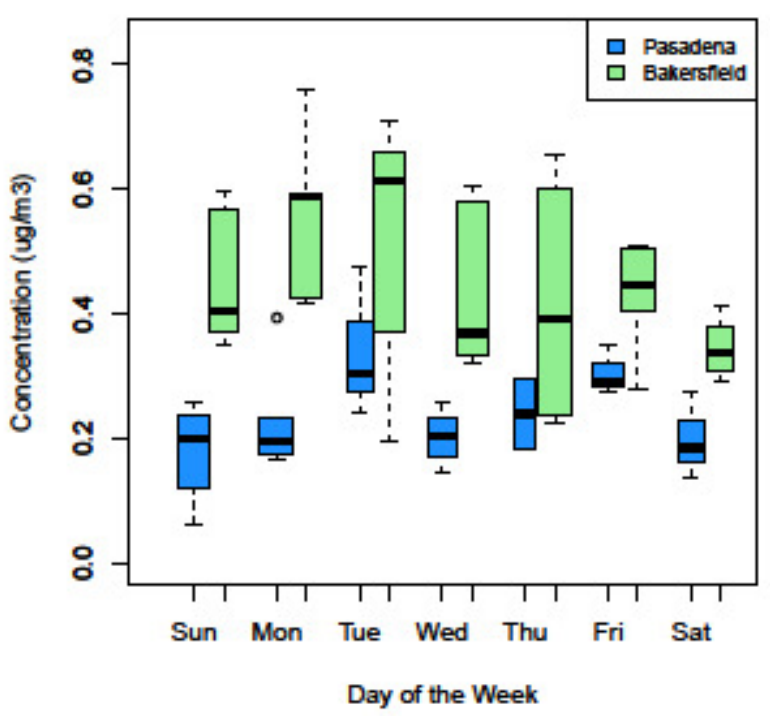


Figure S6. Measured and model estimated contemporary PM2.5 OC fraction at Pasadena and Bakersfield.
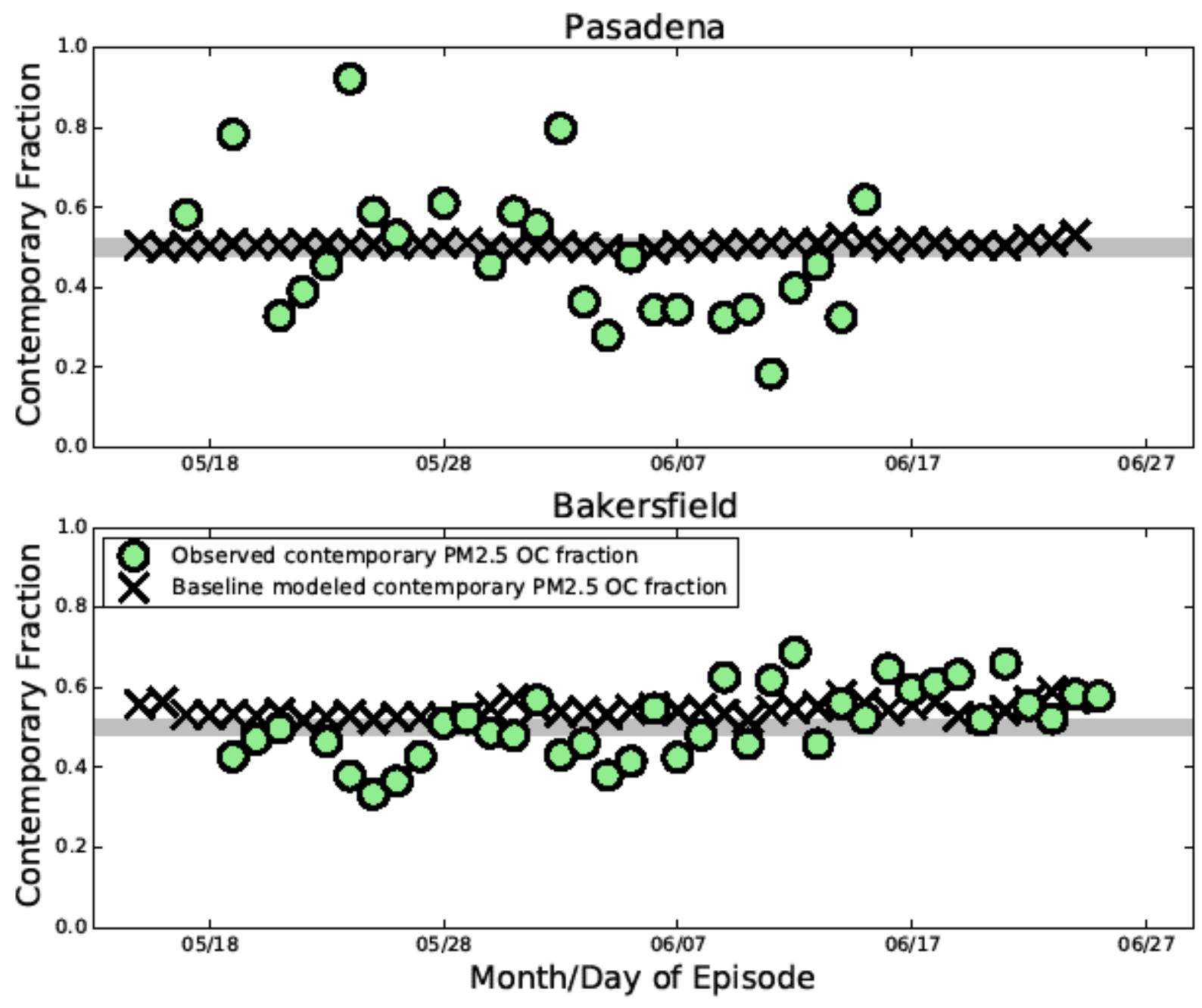
Figure S7. Model predicted and measured $\mathrm{PM}_{2.5}$ elemental carbon at Pasadena and Bakersfield.
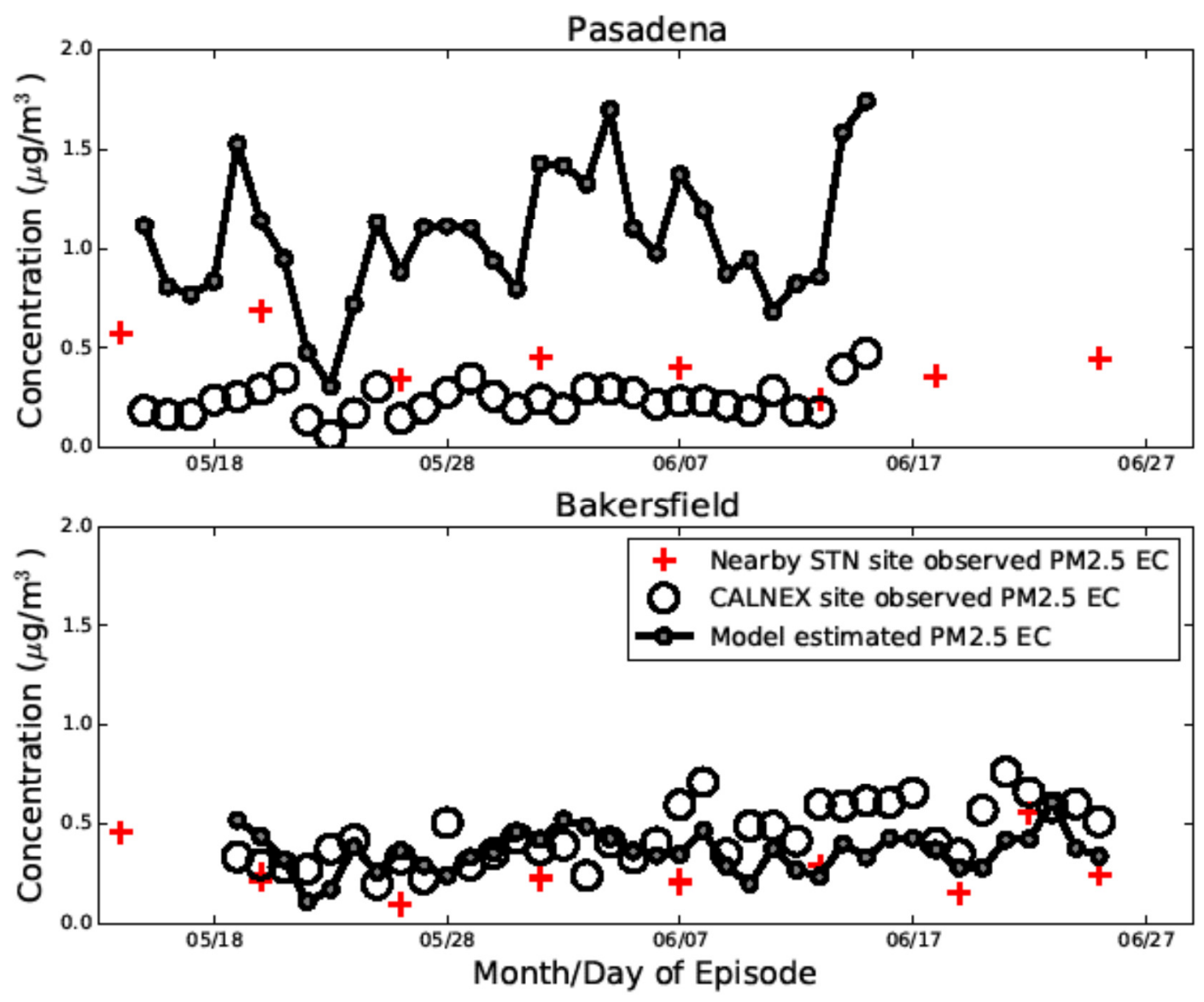
Figure S8. Model and observed hourly VOC (and CO) paired in time and space.
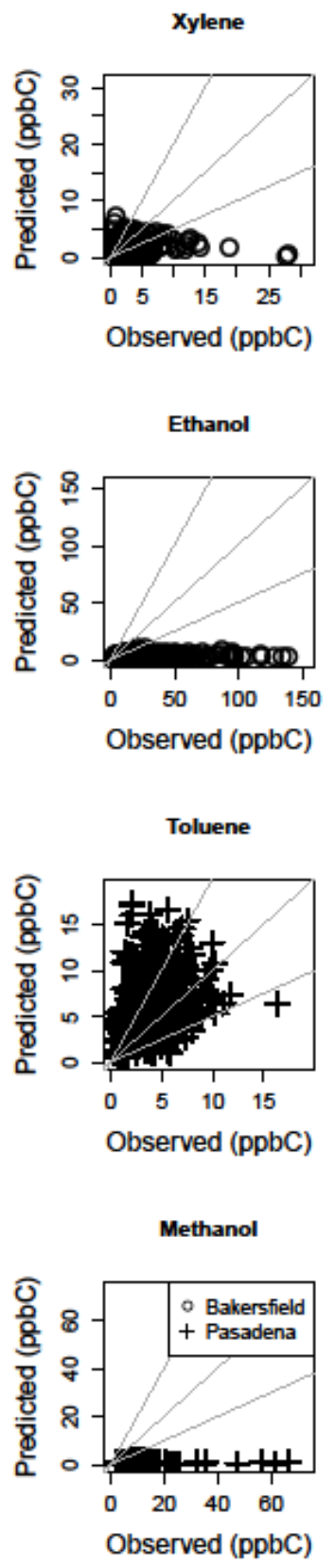
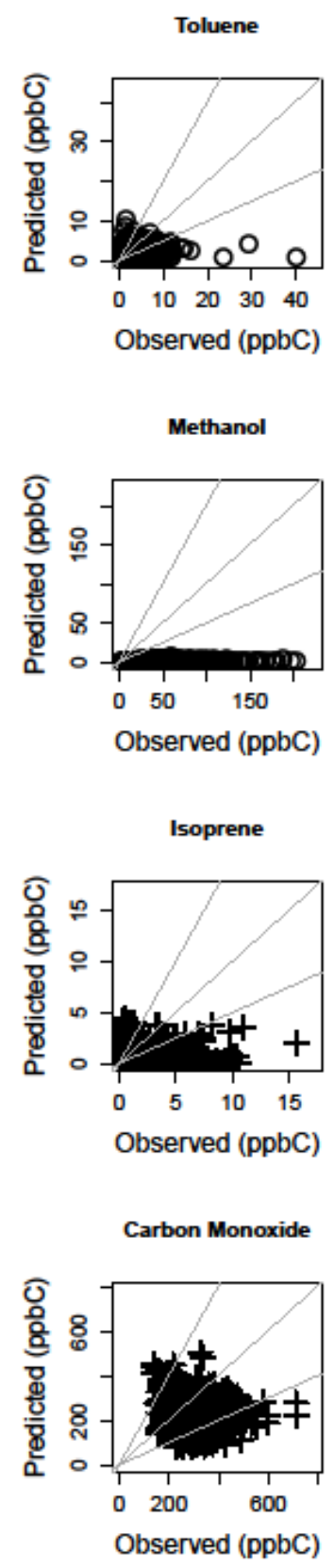
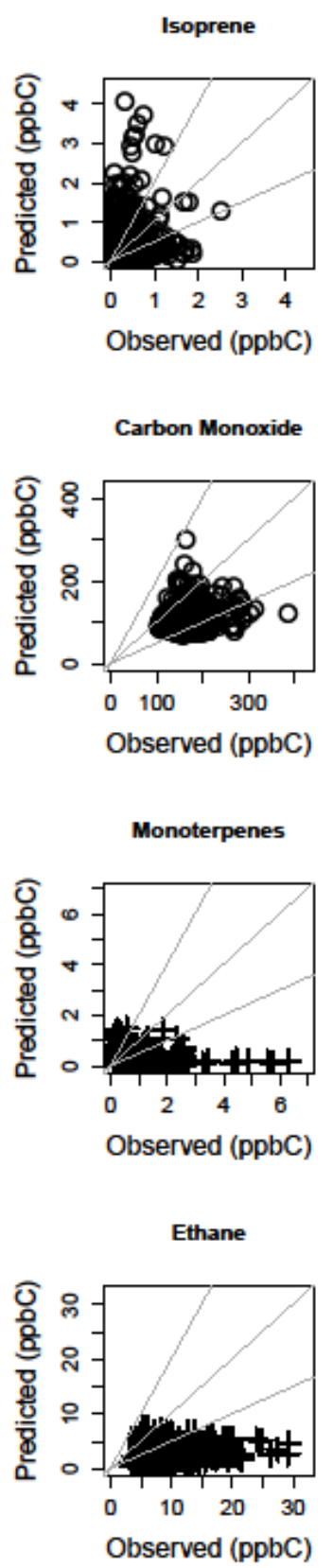
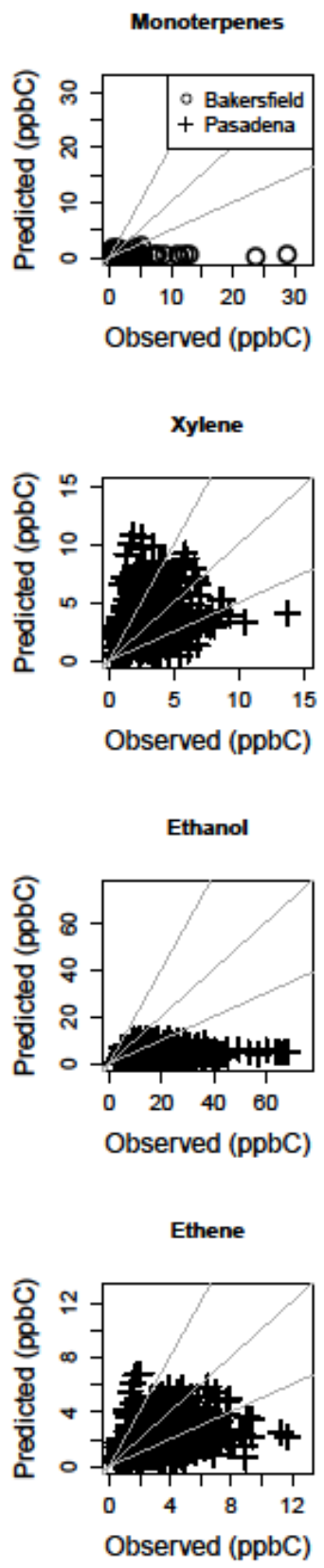
Figure S9. Model and observed mid-morning 3 hour average VOC paired in time and space.
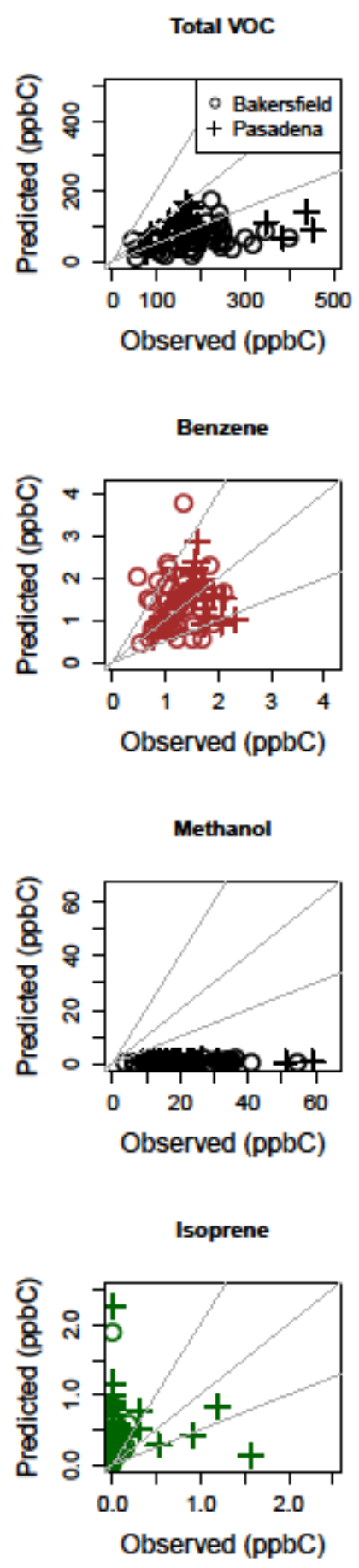
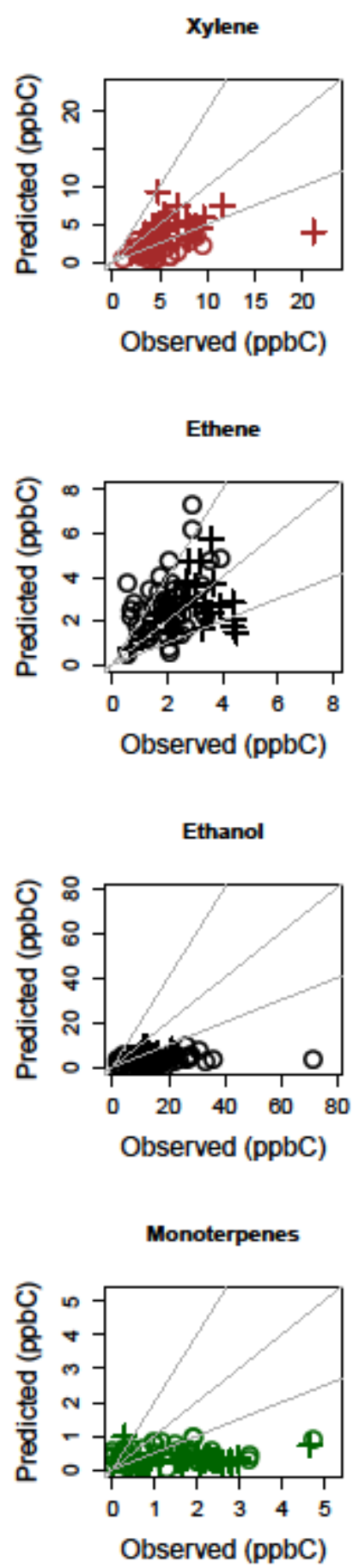
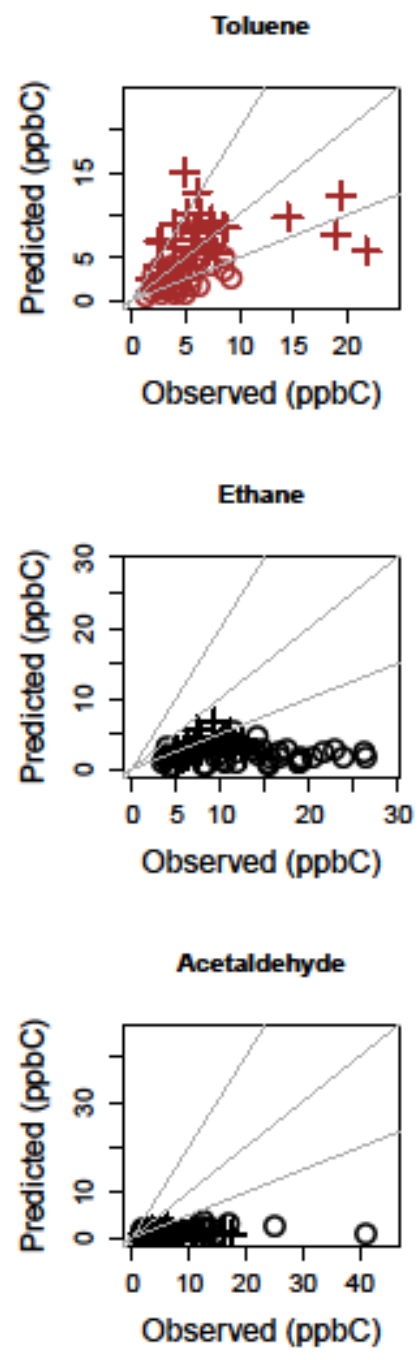
Figure S10a. June average model estimates.

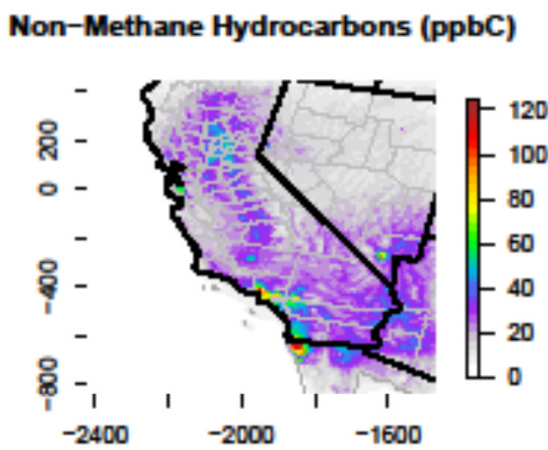

PM2.5 Elemental Carbon (ug/m3)

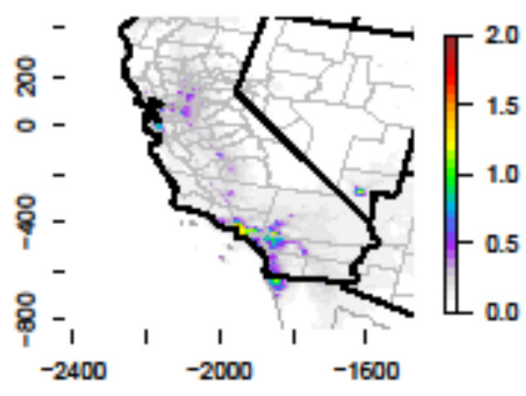

Carbon Monoxide (ppb)

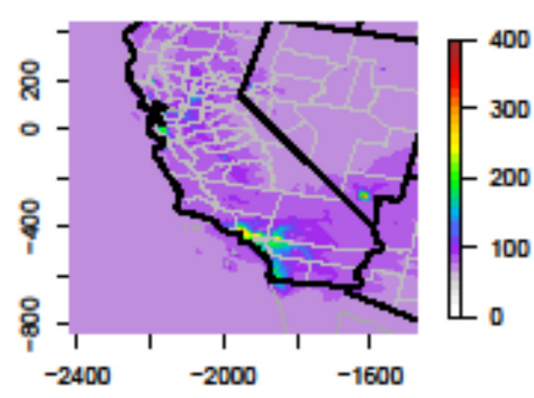

Gas phase semi-volatile VOC (ppbC)

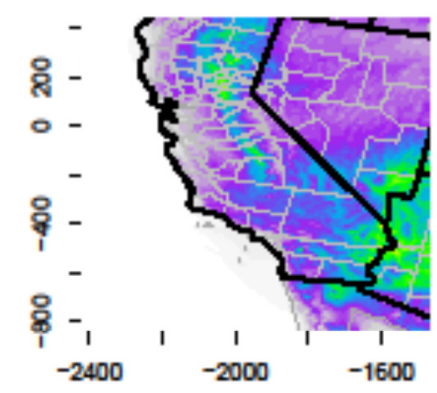

PM2.5 Organic Carbon (ug/m3)
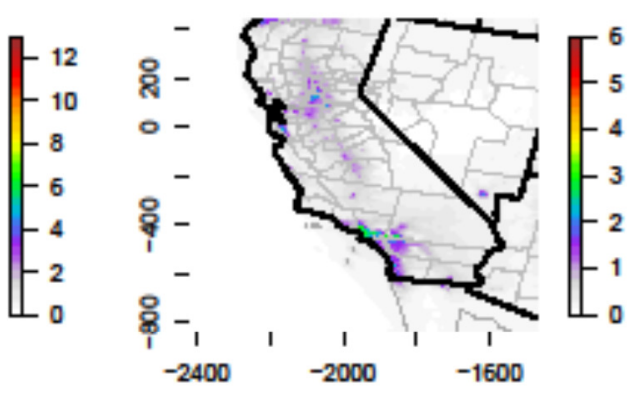

Other Aldehydes (ppb)
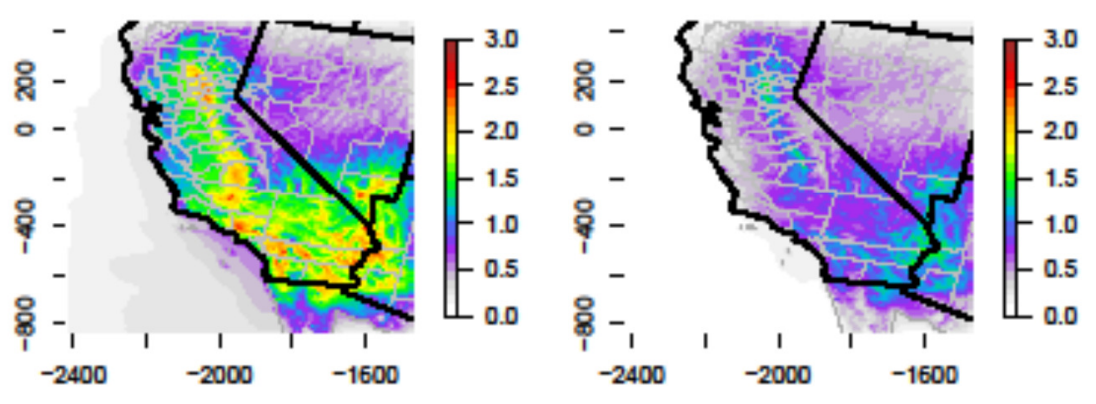

Temperature (F)
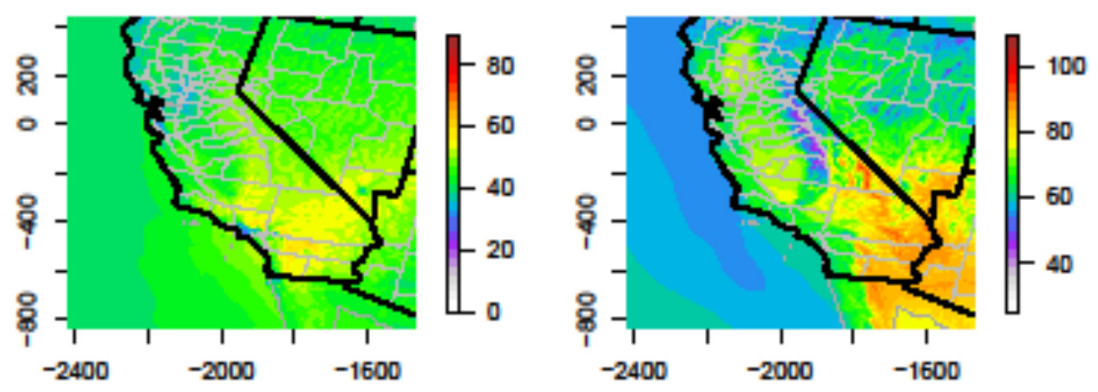
Figure S10b. June average model estimates. Biogenic VOC, semi-volatile products, and SOA.
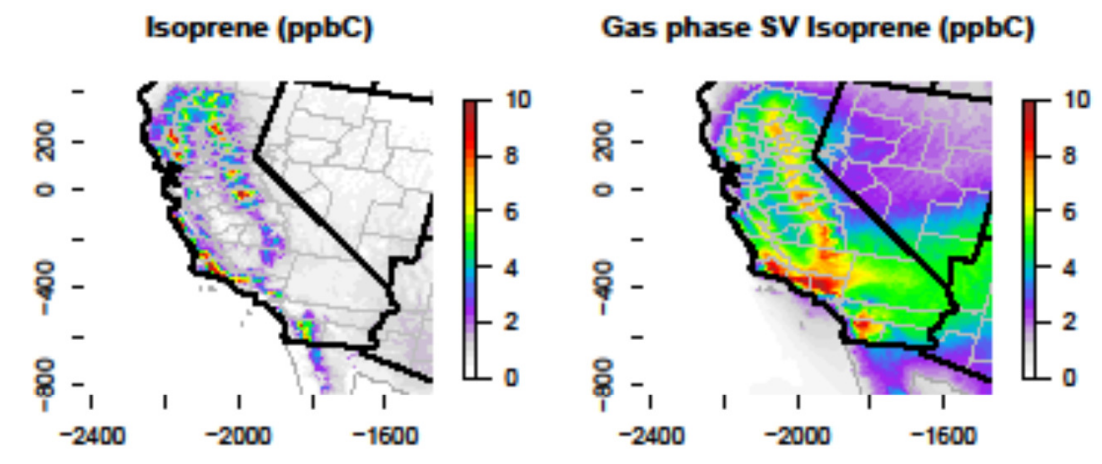

PM2.5 Isoprene SOA (ug/m3)

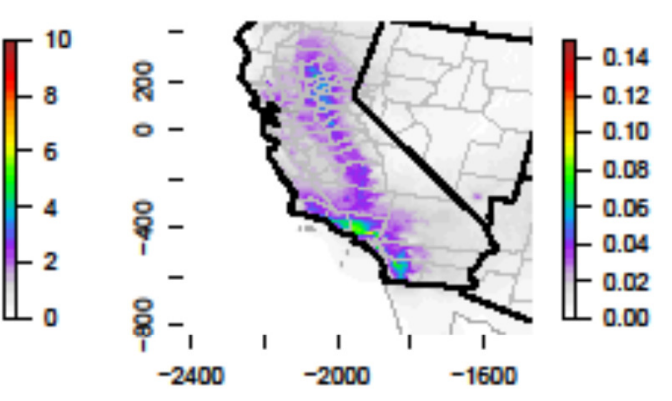

\section{Monoterpenes (ppbC)}

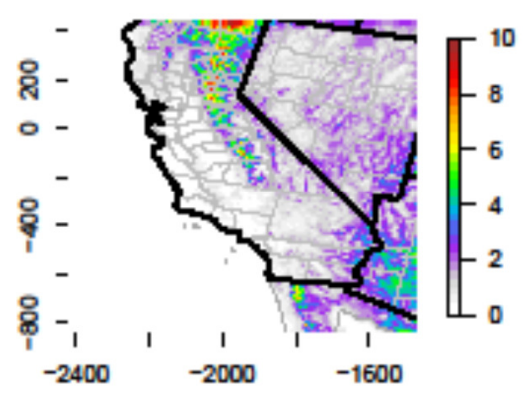

Sesquiterpenes (ppbC)

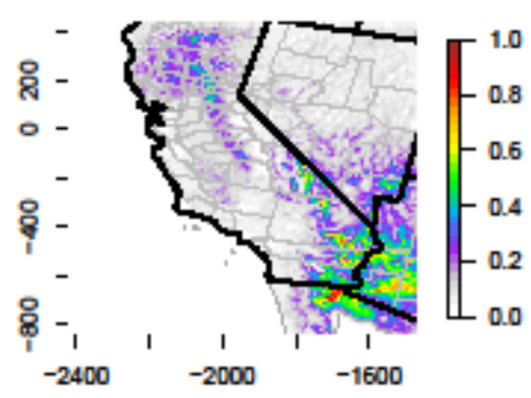

Gas Phase SV Monoterpenes (ppbC)

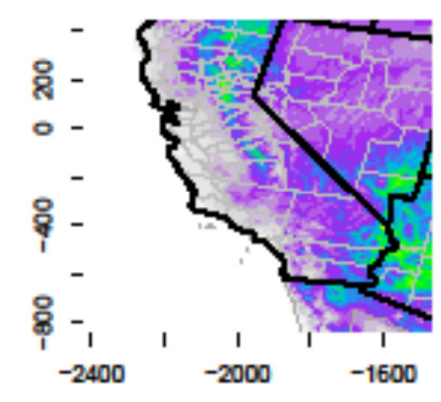

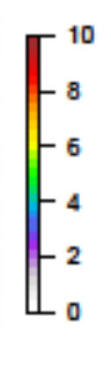

PM2.5 Monoterpene SOA (ug/m3)

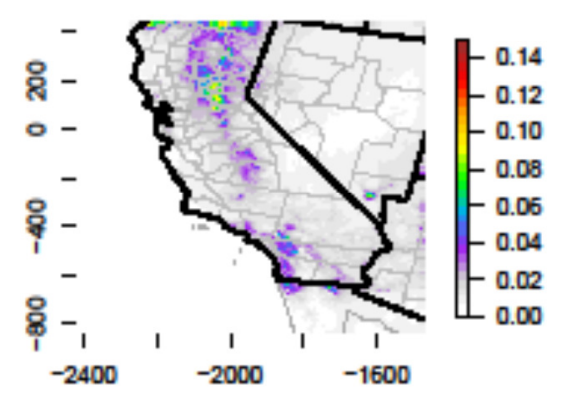

Gas Phase SV Sesquiterpenes (ppbC)

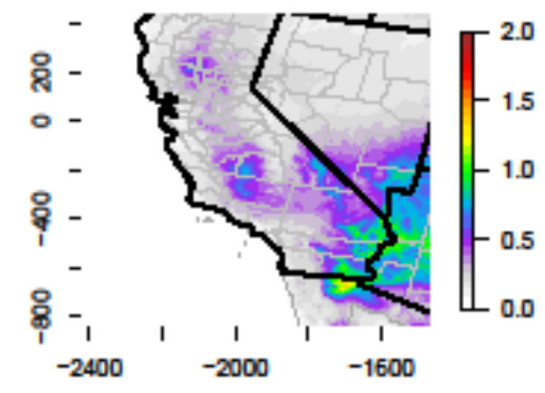

PM2.5 Sesquiterpene SOA (ug/m3)

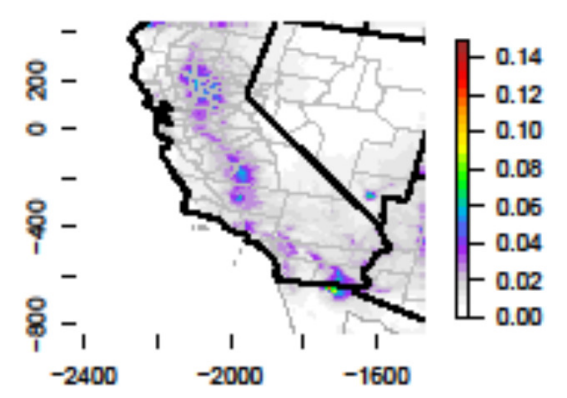


Figure S10c. June average model estimates. Anthropogenic VOC, semi-volatile products, and SOA.

Toluene+Xylene (ppbc)

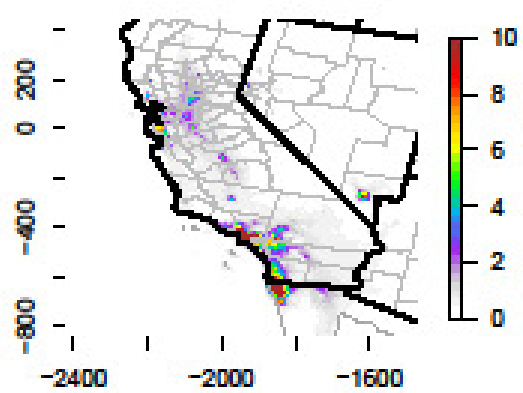

Benzene (ppbc)

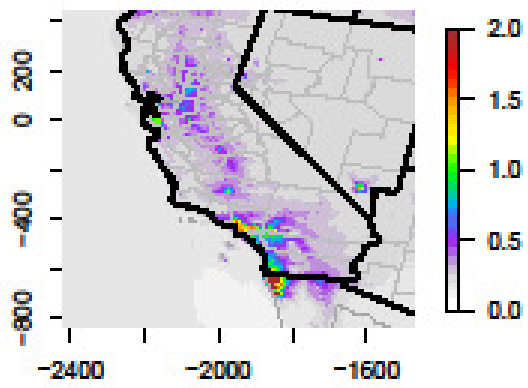

Alkanes (ppbC)

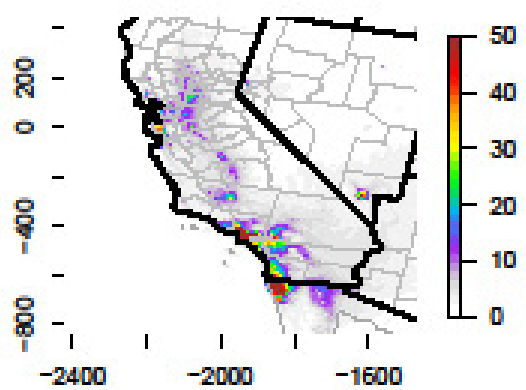

Gas phase SV Toluene+Xylene (ppbC)

PM2.5 Toluene+Xylene SOA (ug/m3)
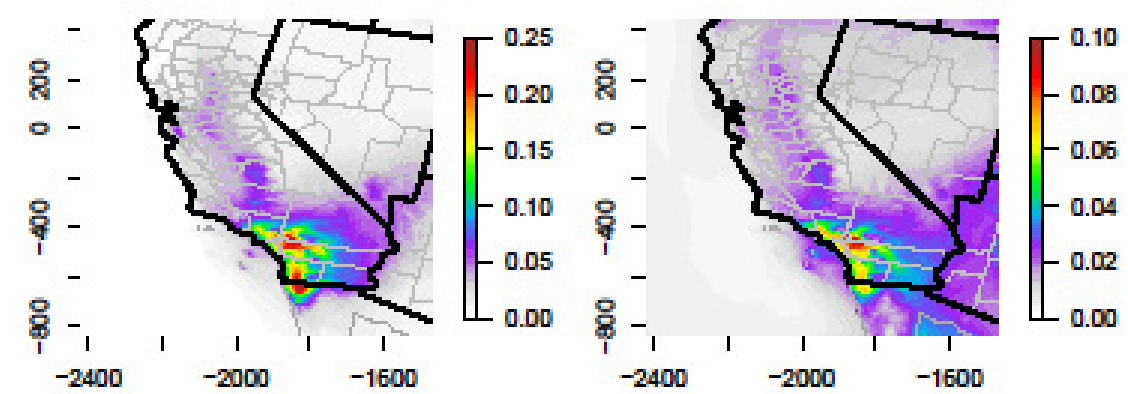

Gas Phase SV Benzene (ppbC)
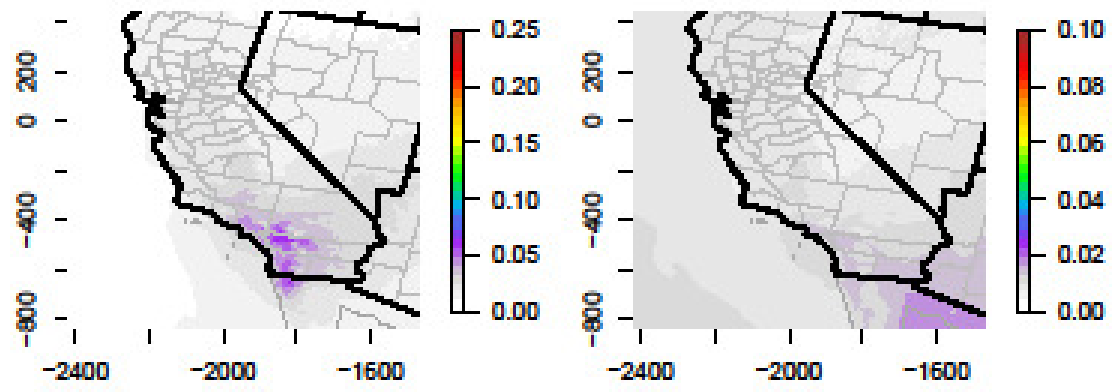

Gas Phase SV Alkanes (ppbC)
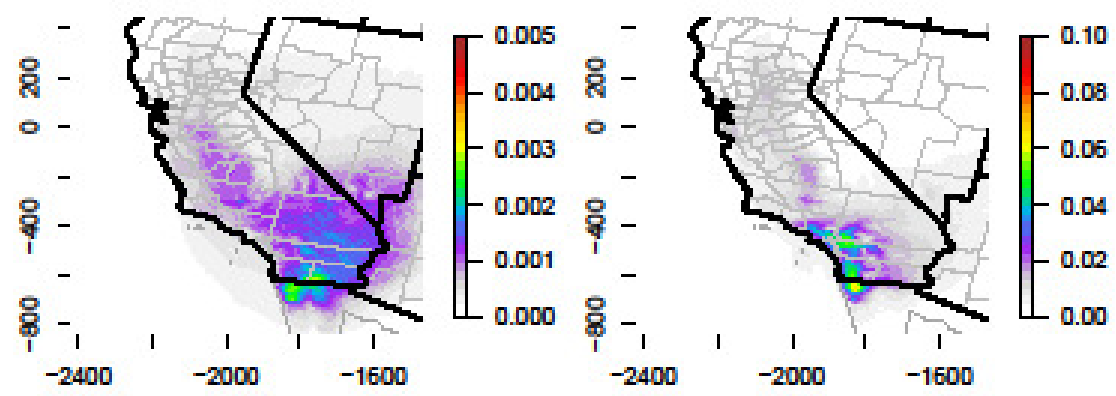
Figure S11. Episode average baseline (top row) and sensitivity (bottom row) model bias and error for PM2.5 organic carbon at CSN (circles) and IMPROVE (squares) sites. The large underestimate at the location in northeast California is related to model underestimates of elevated concentrations during a cold period in this area which may have resulted in increased residential fuel combustion. In general, the model underestimates organic carbon, most notably in urban areas. Rural areas dominated by biogenic sources show minimal bias and error.

Average PM2.5 Organic Carbon Bias

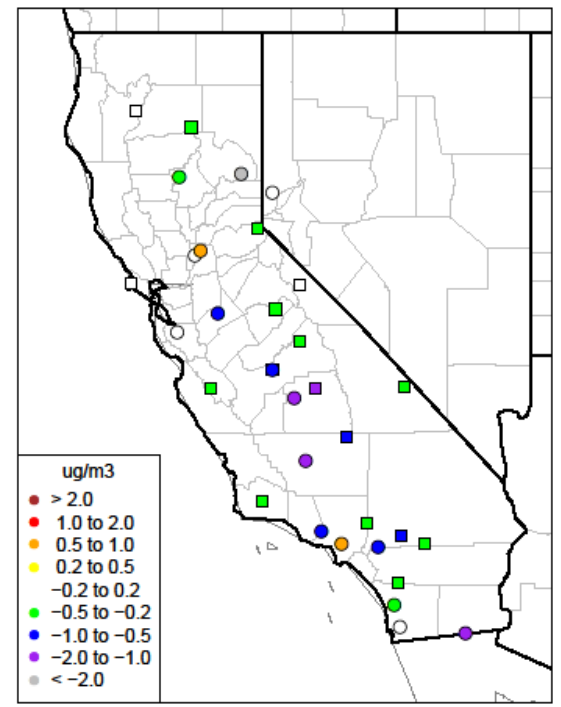

Average PM2.5 Organic Carbon Error

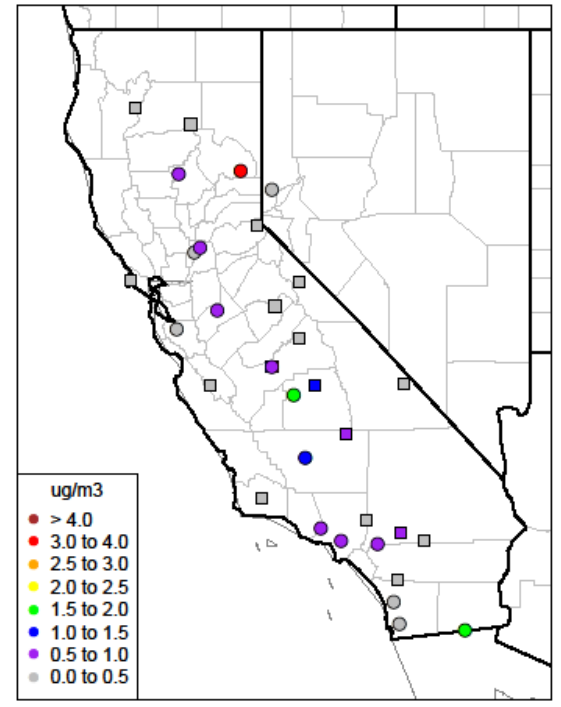

Average PM2.5 Organic Carbon Bias

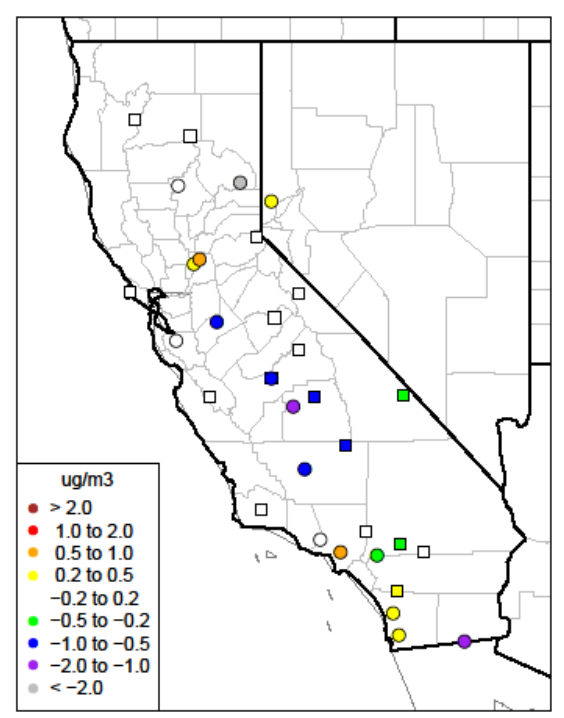

Average PM2.5 Organic Carbon Error

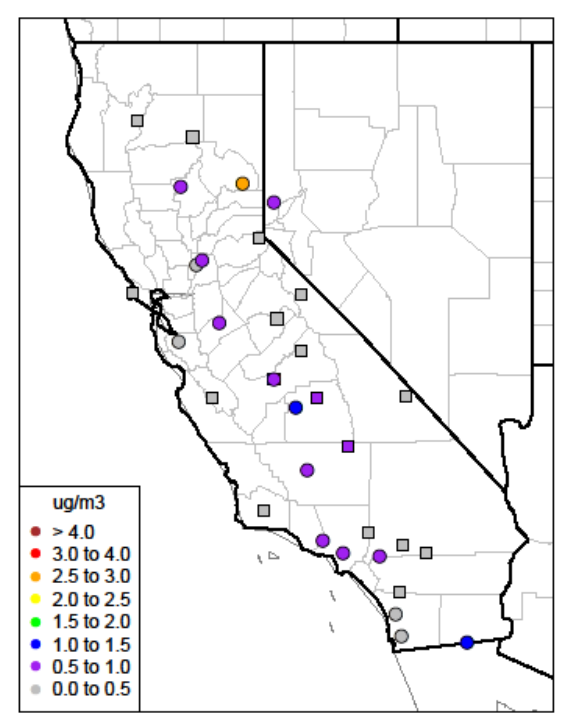




\section{Sampling and Analysis Methods}

CalNex ground measurements took place in Pasadena, CA from 15 May - 15 June 2010 and in Bakersfield, CA from 15 May - 30 June 2010. Filter samples for SOA are integrated for 23-h periods starting at midnight of the designated sampling day. In total, there are 32 filter samples from Pasadena and 36 from the Bakersfield site. The sampling protocols have been described in detail elsewhere (Kleindienst, Lewandowski et al. 2010). $\mathrm{PM}_{2.5}$ was collected on quartz filters using high volume $\mathrm{PM}_{2.5}$ samplers operated at $0.226 \mathrm{~m}^{3} \mathrm{~min}^{-1}$. Each sampler consists of a $\mathrm{PM}_{2.5}$ inlet (Tisch Environmental, Cleves, $\mathrm{OH}$ ) followed by a 90-mm pre-combusted quartz filter (Pall-Life Sciences, East Hills, NY). Organic carbon denuders were not used in-line for these samples.

For the analysis of the SOA tracer compounds, filters and field blanks were treated using the method described by Kleindienst et al. (Kleindienst, Jaoui et al. 2007). Filters were soxhlet extracted for 24 hours using $125 \mathrm{~mL}$ of a 1:1 (v/v) dichloromethane:methanol mixture. Prior to the extraction, cis-ketopinic acid and tetracosane- $d_{50}$ were added as internal standards. Filter extracts were rotary evaporated to a volume of $1 \mathrm{~mL}$, then evaporated to dryness with ultrazero nitrogen. Extracts were derivatized with 250 $\mu \mathrm{L}$ BSTFA ( $1 \%$ TMCS catalyst) and $100 \mu \mathrm{L}$ pyridine to give a final volume of $350 \mu \mathrm{L}$. The silylated extracts were analyzed by GC-ion trap mass spectroscopy (ITMS) in the methane-CI mode. Further detailed aspects of the analytical methodology have been given by Jaoui et al. (Jaoui, Kleindienst et al. 2004).

The mass spectral analysis for the organic compounds used as secondary molecular tracers has been described (Edney, Kleindienst et al. 2003). The tracer compounds are grouped by major ion fragments (Kleindienst, Jaoui et al. 2007). Since standards do not exist for the majority of these compounds, the concentrations of all of the tracers were measured as ketopinic acid (KPA). GC-MS analysis for the tracer compounds was conducted using the total ion chromatogram (TIC) or, in cases where coelution or extremely weak signals occurred, by a selected ion technique. By this method, a factor is determined from laboratory samples of the non-co-eluted peaks that represent the fraction of the five ion intensity to the total ion intensity for each tracer compound. The use of the five-ion-to-TIC calibration factor was found to give more consistent concentration estimates than found using a single ion.

The actual or simulated TIC area was then used to calculate the tracer concentrations as KPA. An assessment of the accuracy of this technique has been estimated as $60 \%$ for pinic and norpinic acids (Jaoui, Kleindienst et al. 2005), two compounds for which independent standards were produced. The technique should not introduce major uncertainties into the contribution estimates from the field data, since the same analytical procedures were used to establish the laboratory-based mass fractions, thus, compensating for systematic errors found in laboratory and field samples. For the determination of the total carbon, a $1.45 \mathrm{~cm}^{2}$ punch was taken from a representative quartz filter and analyzed using the National Institute of Occupational Safety and Health (NIOSH) or thermal-optical transmittance (TOT) method, as described by Birch and Cary (Birch and Cary 1996). Values for OC were corrected for filter background levels. The minimum detect limit for the SOA tracer species is $0.1 \mathrm{ng} / \mathrm{m}^{3}$.

Canisters for volatile organic compound (VOC) analysis were also collected at the two sites. A total of 41 samples were collected at the Bakersfield site and 31 at Pasadena. Samples were collected in evacuated (ca. 1 atm below ambient pressure) 6-liter canisters using Entech CS1200 samplers. Attached to the CS1200 samplers were Entech TM1100 systems that consisted of a battery operated off/on valve activated by a timer control element. The valve was open for a 3-h collection during the 6:00 - 9:00 a.m. (local daylight time) period. The samples were analyzed by GC-FID and reported compounds were 
identified by a GC retention time index using a calibration table (CALTABLE) of 402 VOCs developed specifically for GC system. Compounds equal to or less than the detection limit of $0.05 \mathrm{ppbC}$ were defined as zero for comparison presentation of paired experimental and modeled estimates.

\section{References}

Birch, M. E. and R. A. Cary (1996). "Elemental carbon-based method for monitoring occupational exposures to particulate diesel exhaust." Aerosol Sci. Technol. 25: 221-241.

Edney, E. O., T. E. Kleindienst, T. S. Conver, C. D. Mclver, E. W. Corse and W. S. Weathers (2003). "Polar organic oxygenates in PM2.5 at a southeastern site in the United States." Atmospheric Environment 37(28): 3947-3965.

Jaoui, M., T. E. Kleindienst, M. Lewandowski and E. O. Edney (2004). "Identification and quantification of aerosol polar oxygenated compounds bearing carboxylic or hydroxyl groups. 1. Method development." Analytical Chemistry 76(16): 4765-4778.

Jaoui, M., T. E. Kleindienst, M. Lewandowski, J. H. Offenberg and E. O. Edney (2005). "Identification and quantification of aerosol polar oxygenated compounds bearing carboxylic or hydroxyl groups. 2. Organic tracer compounds from monoterpenes." Environmental Science \& Technology 39(15): 5661-5673.

Kleindienst, T. E., M. Jaoui, M. Lewandowski, J. H. Offenberg, C. W. Lewis, P. V. Bhave and E. O. Edney (2007). "Estimates of the contributions of biogenic and anthropogenic hydrocarbons to secondary organic aerosol at a southeastern US location." Atmospheric Environment 41(37): 8288-8300.

Kleindienst, T. E., M. Lewandowski, J. H. Offenberg, E. O. Edney, M. Jaoui, M. Zheng, X. A. Ding and E. S. Edgerton (2010). "Contribution of Primary and Secondary Sources to Organic Aerosol and PM2.5 at SEARCH Network Sites." Journal of the Air \& Waste Management Association 60(11): 1388-1399. 


\section{CMAQ AE6 treatment for SOA presented by volatility and O:C ratio}

Modeled organic aerosol species, semi-volatile partitioning gas phase analogs, and VOC precursors are matched with a volatility bin assignment based on saturation vapor pressure ( $\left.C^{*}\right)$ (Table S3). $C^{*}$ values for semi-volatile and aerosol species are taken from (Carlton et al., 2010) and calculated for gas-phase VOCs based on (Pankow et al., 1994) (Table S3 and Equation S1). The saturation vapor pressure of sesquiterpenes has not been measured and bin assignment is somewhat arbitrary; sesquiterpenes are placed in the $\log \left(C^{*}\right)=5$ bin, two bins lower than monoterpenes and four bins lower than isoprene. Model reference $C^{*}$ values are translated to local conditions at each sampling location by employing the species-specific enthalpy of vaporization $\left(\Delta \mathrm{H}_{\mathrm{vap}}\right)$. Mass concentrations of gas-phase species were calculated from the CMAQ reported mixing ratios $\left(\mathrm{ppb}_{\mathrm{v}}\right)$ :

$$
C_{i}\left(\frac{\mu g}{m^{3}}\right)=X_{i} \frac{P}{R T} M W_{i}
$$

Where $\mathrm{X}_{i}$ is the gas phase mixing ratio in $\mathrm{ppb}_{v}$ for species $i, \mathrm{P}$ and $\mathrm{T}$ are the location specific instantaneous pressure and temperature respectively, $R$ is the ideal gas constant, and $\mathrm{MW}_{i}$ is the species molecular weight.

CMAQ predictions of organic material during CalNex are dominated by gas phase species. This is generally true and consistent with early measurements in California (Fraser et al., 1996). Episode average gas and particle organic carbon estimated by CMAQ for each ground site are shown in Figure S11 by saturation vapor pressure. Most of the carbon mass is either in the gas phase or non-volatile aerosol. Mass in the semi-volatile space is largely in the gas-phase. This suggests the potential exists for additional modeled SOC but this space is difficult to constrain due to limited available gas phase measurements. This Figure also shows gaps in the model representation of $\mathrm{PM}_{2.5}$ organic carbon volatility distribution. Additional precursors with a saturation vapor pressure less than $10^{8} \mathrm{\mu g} / \mathrm{m}^{3}$ (such as IVOCS) could ameliorate some of the SOC under prediction (Shrivastava et al., 2008).

Smog chamber experiments conducted at high mass loadings and the SOC parameterizations developed from those experiments, and used in $\mathrm{CMAQ}$, may be a contributing factor to the absence of material in low volatility bins, possibly due to bin mis-assignment (Stanier et al., 2008). It would also seem that some material mapped to the "non-volatile" bin actually exhibit some partitioning and should be elsewhere in the distribution, i.e., $-4<\log _{10} \mathrm{C}^{*}<-1$. Missing SOC from PAHs (the naphthalene tracer) would contribute organic material to bins 0 and 2 with an 0:C ratio 0.5 (Chan et al., 2009b; Pye and Pouliot, 2012) and would not ameliorate the empty gaps. As noted previously, the modeling system does well at replicating total VOC but tends to underestimate aerosol carbon at these sites during this time period. For model applications requiring yields of species with saturation concentrations less than $0.1 \mu \mathrm{g} / \mathrm{m}^{3}$, experiments must be able to measure similarly low concentrations to provide robust parameters (Stanier et al., 2008).

\section{References}

Carlton, A.G., Bhave, P.V., Napelenok, S.L., Edney, E.O., Sarwar, G., Pinder, R.W., Pouliot, G.A., Houyoux, M., 2010. Treatment of secondary organic aerosol in CMAQv4.7. Environmental Science and Technology 44, 8553-8560.

Chan, A.W.H., Kautzman, K.E., Chhabra, P.S., Surratt, J.D., Chan, M.N., Crounse, J.D., Kuerten, A., Wennberg, P.O., Flagan, R.C., Seinfeld, J.H., 2009. Secondary organic aerosol formation from 
photooxidation of naphthalene and alkylnaphthalenes: implications for oxidation of intermediate volatility organic compounds (IVOCs). Atmospheric Chemistry and Physics 9, 3049-3060.

Fraser, M.P., Grosjean, D., Grosjean, E., Rasmussen, R.A., Cass, G.R., 1996. Air quality model evaluation data for organics .1. Bulk chemical composition and gas/particle distribution factors. Environmental Science \& Technology 30, 1731-1743.

Pankow, J.F., Isabelle, L.M., Buchholz, D.A., Luo, W.T., Reeves, B.D., 1994. Gas Particle Partitioning of Polycyclic Aromatic Hydrocarbons and Alkanes to Environmental Tobacco Smoke. Environmental Science \& Technology 28, 363.

Pye, H.O.T., Pouliot, G.A., 2012. Modeling the Role of Alkanes, Polycyclic Aromatic Hydrocarbons, and Their Oligomers in Secondary Organic Aerosol Formation. Environmental Science \& Technology.

Shrivastava, M.K., Lane, T.E., Donahue, N.M., Pandis, S.N., Robinson, A.L., 2008. Effects of gas particle partitioning and aging of primary emissions on urban and regional organic aerosol concentrations. Journal of Geophysical Research: Atmospheres (1984-2012) 113.

Stanier, C.O., Donahue, N.M., Pandis, S.N., 2008. Parameterization of secondary organic aerosol mass fractions from smog chamber data. Atmospheric Environment 42, 2276-2299. 


\section{Volatility Estimation}

Table S3. Calculation of volatility bin for gas phase organic species.

\begin{tabular}{|c|c|c|c|c|c|}
\hline Species Name & $\begin{array}{c}\text { Molecular } \\
\text { Weight } \\
\text { (g/gmol) }\end{array}$ & $\begin{array}{c}\text { Vapor Pressure } \\
\text { (mmHg) }\end{array}$ & $\begin{array}{c}\text { Saturation Vapor } \\
\text { Pressure }\left(c^{*}\right)\end{array}$ & $\log \left(c^{*}\right)$ & Note \\
\hline ISOP & 68.12 & 550 & $2.05 \mathrm{E}+09$ & 9.31 & \\
\hline ALK2,ALK3,ALK4 & 57.6 & 100 & $3.15 E+08$ & 8.50 & $\mathrm{MW}=$ average of $36.7,58.6$, and 77.6 \\
\hline MGLY & 108 & 27 & $1.60 \mathrm{E}+08$ & 8.20 & Hydrated methylgloxal (higher MW) \\
\hline MGLY & 72.1 & 27 & $1.07 \mathrm{E}+08$ & 8.03 & \\
\hline TOLUENE & 92.1 & 20 & $1.01 \mathrm{E}+08$ & 8.00 & \\
\hline GLY & 92 & 18 & $9.06 \mathrm{E}+07$ & 7.96 & Hydrated glyoxal (higher MW) \\
\hline BENZENE & 78 & 20 & $8.54 \mathrm{E}+07$ & 7.93 & \\
\hline GLY & 58.1 & 18 & $5.72 E+07$ & 7.76 & \\
\hline MXYL,OXYL,PXYL & 106.2 & 7 & 4.07E+07 & 7.61 & \\
\hline TERP & 136 & 3.5 & $2.61 \mathrm{E}+07$ & 7.42 & \\
\hline Napthalene & 128.19 & 0.087 & $6.10 \mathrm{E}+05$ & 5.79 & Not included in CMAQv5.0.2 \\
\hline SESQ & 204 & 0.01 & $1.12 \mathrm{E}+05$ & 5.05 & Assumed vapor pressure \\
\hline ATRP2, SV_TRP2 & & & $1.34 \mathrm{E}+02$ & 2.13 & c* from Carlton et al, 2010 \\
\hline AISO1, SV_ISO1 & & & $1.16 \mathrm{E}+02$ & 2.06 & c* from Carlton et al, 2010 \\
\hline ABNZ2, SV_BNZ2 & & & $1.11 \mathrm{E}+02$ & 2.05 & c* from Carlton et al, 2010 \\
\hline AXYL2, SV_XYL2 & & & $3.45 \mathrm{E}+01$ & 1.54 & c* from Carlton et al, 2010 \\
\hline ASQT, SV_SQT & & & $2.50 \mathrm{E}+01$ & 1.40 & c* from Carlton et al, 2010 \\
\hline ATOL2, SV_TOL2 & & & $2.13 E+01$ & 1.33 & c* from Carlton et al, 2010 \\
\hline ATRP1, SV_TRP1 & & & $1.48 \mathrm{E}+01$ & 1.17 & c* from Carlton et al, 2010 \\
\hline ATOL1, SV_TOL1 & & & $2.33 E+00$ & 0.37 & c* from Carlton et al, 2010 \\
\hline AXYL1, SV_XYL1 & & & $1.31 \mathrm{E}+00$ & 0.12 & c* from Carlton et al, 2010 \\
\hline AISO2, SV_ISO2 & & & $6.17 \mathrm{E}-01$ & -0.21 & c* from Carlton et al, 2010 \\
\hline ABNZ1, SV_BNZ1 & & & $3.02 \mathrm{E}-01$ & -0.52 & c* from Carlton et al, 2010 \\
\hline AALK, SV_ALK & & & $2.00 \mathrm{E}-02$ & -1.70 & c* from Carlton et al, 2010 \\
\hline
\end{tabular}

\section{Equation S1.}

$$
C_{i}^{*}=\frac{10^{6} M W_{i} \xi_{i} p_{L, i}^{o}}{R T}=\frac{10^{6}\left(\frac{\mu g}{g}\right) \times M W_{i}\left(\frac{g}{g m o l}\right) \times \xi_{i} \times p_{L, i}^{o}(m m H G)}{62.36\left(\frac{L m m H G}{K m o l}\right) \times 293(K) \times \frac{m^{3}}{1000 L}}
$$

Note that $\xi_{i}$ is assumed to be 1 . This assumption is useful as an index for comparison among species but does not provide a complete description of the partitioning potential of water-soluble organic species. 


\section{Carbon and Oxygen Relationships}

Table S4. Comparison of O:C ratio estimated from the assigned OM:OC ratios and estimated by counting the number of carbon, oxygen and hydrogen atoms.

\begin{tabular}{|c|c|c|c|c|c|c|c|}
\hline Species & MW & OM/OC & $\begin{array}{c}\text { \# of C } \\
\text { derived from } \\
\text { parent compound }\end{array}$ & $\begin{array}{c}\text { \# of } \mathbf{O} \\
\text { integer dervied } \\
\text { from MW less } \\
\text { carbon mass } \\
\end{array}$ & $\begin{array}{c}\text { \# of } \mathbf{H} \\
\text { integer dervied from } \\
\text { MW less carbon \& } \\
\text { oxygen mass }\end{array}$ & $\begin{array}{c}\text { O:C } \\
\text { calculated from } \\
\text { suspected } \\
\text { chemical makeup }\end{array}$ & $\begin{array}{c}\text { O:C } \\
(\mathrm{OM} / \mathrm{OC}-1)^{*}(3 / 4)\end{array}$ \\
\hline AlSO1 & 96 & 1.6 & 5 & 2 & 4 & 0.40 & 0.45 \\
\hline AlSO2 & 96 & 1.6 & 5 & 2 & 4 & 0.40 & 0.45 \\
\hline ABNZ1 & 144 & 2 & 6 & 4 & 8 & 0.67 & 0.75 \\
\hline ABNZ2 & 144 & 2 & 6 & 4 & 8 & 0.67 & 0.75 \\
\hline ABNZ3 & 144 & 2 & 6 & 4 & 8 & 0.67 & 0.75 \\
\hline AALK & 150 & 1.56 & 8 & 3 & 6 & 0.38 & 0.42 \\
\hline AlSO3 & 162 & 2.7 & 5 & 6 & 6 & 1.20 & 1.28 \\
\hline ATOL1 & 168 & 2 & 7 & 5 & 4 & 0.71 & 0.75 \\
\hline ATOL2 & 168 & 2 & 7 & 5 & 4 & 0.71 & 0.75 \\
\hline ATOL3 & 168 & 2 & 7 & 5 & 4 & 0.71 & 0.75 \\
\hline ATRP1 & 168 & 1.4 & 10 & 3 & 0 & 0.30 & 0.30 \\
\hline ATRP2 & 168 & 1.4 & 10 & 3 & 0 & 0.30 & 0.30 \\
\hline AOLGA & 176.4 & 2.1 & 8 & 5 & 0 & 0.63 & 0.83 \\
\hline AORGC & 177 & 2 & 3 & 8 & 13 & 2.67 & 0.75 \\
\hline AXYL1 & 192 & 2 & 8 & 6 & 0 & 0.75 & 0.75 \\
\hline AXYL2 & 192 & 2 & 8 & 6 & 0 & 0.75 & 0.75 \\
\hline AXYL3 & 192 & 2 & 8 & 6 & 0 & 0.75 & 0.75 \\
\hline AOLGB & 252 & 2.1 & 10 & 8 & 4 & 0.80 & 0.83 \\
\hline ASQT & 378 & 2.1 & 15 & 12 & 6 & 0.80 & 0.83 \\
\hline
\end{tabular}

NOTE: This analysis is somewhat limited in its application to AOLGA, AOLGB and AORGC. AOLGA and AOLGB represent oligomerization with a potentially changing number of carbon atoms. AORGC represents carboxylic acid and high molecular weight compounds (max $O: C$ of 2). The assigned MW of ATRP1, ATRP2, AXYL1, AXYL2, AXYL3 and AOLGA is not able to accommodate $\mathrm{H}$ atoms consistent with the assigned OM:OC ratios. 
Figure S11. Episode average CMAQ organic mass (baseline on left and sensitivity on right) plotted by saturation vapor pressure. Gaps in the distribution are associated with chemical properties that potentially provide insight regarding the identity missing organic aerosol mass noted in CMAQ predictions. Model baseline estimates shown at left and sensitivity simulation at right.
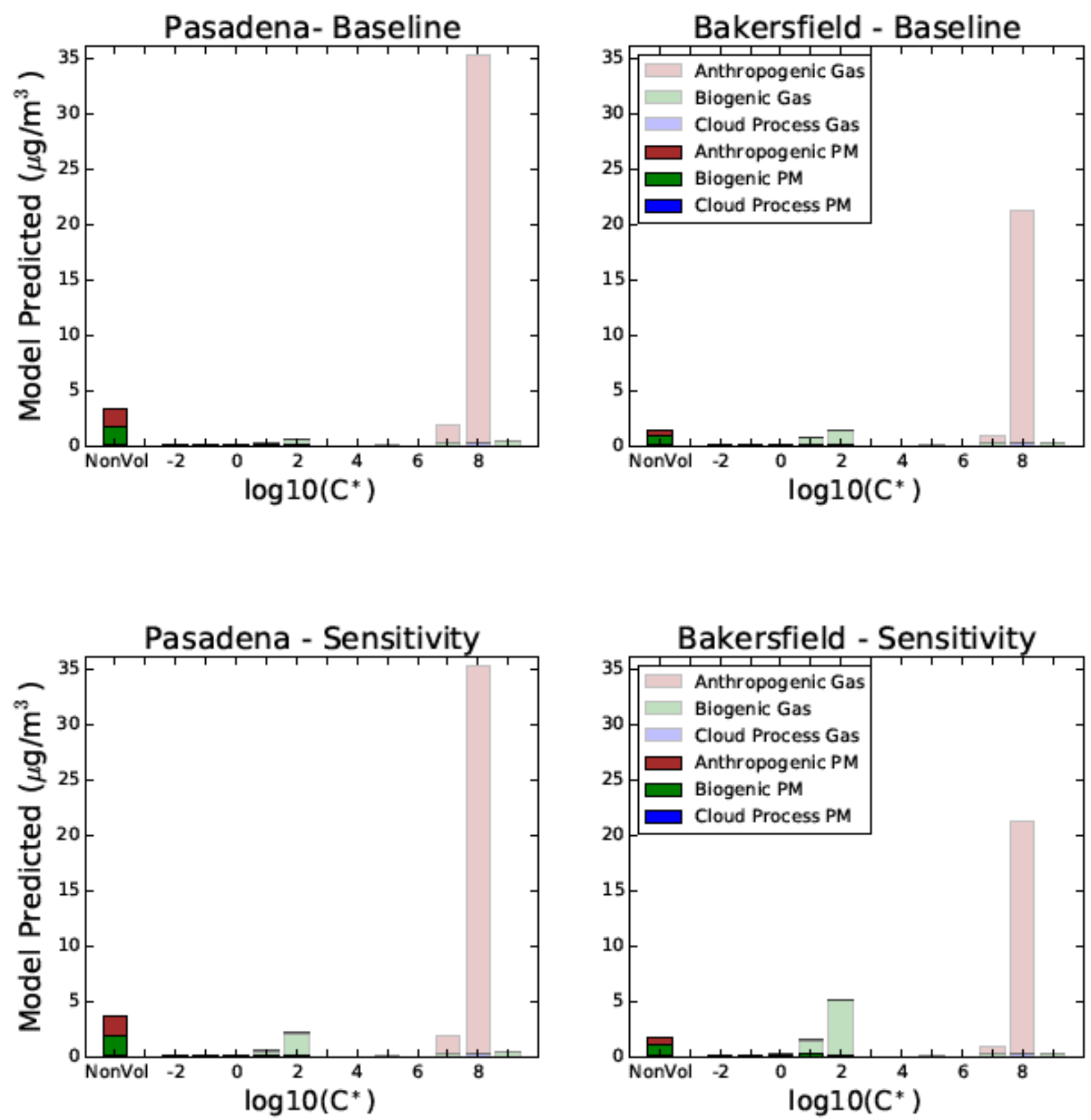